\title{
1 Influence of demolition waste fine particles on the properties of recycled aggregate
} 2 masonry mortar

3

4 Abstract

5 This paper analyses the influence of the fine fraction of two types of construction and 6 demolition waste (CDW1 and CDW2) on the properties of recycled aggregates (RA) and 7 masonry mortars. The CDW1's main component was ceramic while the CDW2 were 8 concrete. Three different kinds of fine RA were produced from each source of CDW; the

9 first type was produced by only using the fraction finer than $4.76 \mathrm{~mm}$, the second one by 10 employing only the coarser fraction than $4.76 \mathrm{~mm}$, and the third type was a mix of both 11 fractions of CDW. The masonry mortars were produced employing the $100 \%$ substitution 12 of natural aggregates. The results show that all the recycled mortars achieved a higher 13 water retentivity capacity than that of the conventional mortars. However, the sole use of 14 the fine fraction of the CDW was found to have a deleterious effect over the hardened 15

\section{Highlights}

- Two sources of CDW, one with ceramic and other with concrete as main components, were employed.

- Three different RA were obtained from two different sources of CDW.

- Masonry mortars employing $100 \%$ of recycled aggregate were validated.

- Ceramic high content recycled aggregates mortars achieved the most adequate properties.

- The employment of the coarse fraction of the CDW guarantee high quality aggregates for masonry mortar.

Keywords: Masonry mortar; fine recycled aggregate; recycled aggregate mortar; construction and demolition waste; fresh mortar properties; mechanical properties. 


\section{Abbreviations}

34 CDW - Construction and demolition waste

35 FRA - Fine recycled aggregate

36 LH - Lime hydrate

$37 \quad$ LF - Limestone filler

38 RA - Recycled aggregate

$39 \mathrm{w} / \mathrm{c}$ - water/cement

\section{Introduction}

The use of recycled aggregates obtained from the recycling of construction and demolition waste (CDW) is a sustainable alternative to the employment of natural aggregates within the construction industry [1]. This alternative not only allows for the protection of natural resources but is also instrumental in the reduction of areas used for landfill [2]. There have been many studies with respect to the mentioned environmental benefits [3-6], although most of the studies have been focused on the use of recycled aggregates for concrete production [7-12]. Several researchers have also studied the applicability of fine recycled aggregates (FRA) for mortar production due to the high amount of FRA produced as a result of the CDW treatment process [13-20].

Most of the mortar mixes manufactured with higher percentages of recycled aggregate presented lower mechanical properties than those of conventional mortar $[13,14,16,17,19,20]$. However, certain authors have established that there were minor influences on the properties of mortar mixes produced with a replacement ratio of up to $20 \%$ [21,22], $25 \%$ [19] or $40 \%$ [15] of recycled aggregate in substitution of natural aggregate. According to several researches [23-26] the improvements on the mortars' properties were also achieved when fine ceramic and concrete aggregates were employed

5 in the mortar production or the quality of the recycled aggregates were improved after 59 their treatment [27]. 
60 The CDW, which can be recycled, is available in numerous countries as a result of human intervention or natural disasters [28]. According to the information obtained from the Cuban National Statistics and Information Office, approximately $1000 \mathrm{~m}^{3}$ of CDW is generated per day in Havana. The largest volume of CDW being located in landfill sites, which effectively makes it unusable for recycling due to the resulting mixing of materials and consequent contamination [29]. In Cuba, uncontaminated waste is not recycled due to deficiencies in adequate technological infrastructures as well as a lack of an adequate policy with respect to the management of this type of waste [30].

The natural aggregate quarries located near the city are almost depleted as a result of their over exploitation. Consequently, natural aggregates have to be obtained from new quarries which are a long distance away from the city, with the following consequences of higher economic costs as well as having a negative environmental impact on the local landscape [30].

Masonry mortars are widely employed in the construction of buildings in Havana, in general social housing, which is the cause of the highest aggregate consumption. The mechanical properties required for rendering or bonding mortars, according to the Cuban standard [31], are relatively low (less than $10 \mathrm{MPa}$ of compression strength), allowing the use of a low cement content in the mortar manufacture.

As a direct consequence of the lack of natural fine aggregates the locals in Havana have used for the maintenance and renovation of their buildings recycled material with fractions finer than $5 \mathrm{~mm}$ (without crushing) obtained directly from demolished or collapsed building waste. Its use is carried out without undergoing a process of selection and treatment, as a consequence of which this fine aggregate material is often of poor quality due to its contamination by detrimental material. Fig. 1 shows several images of both sources of CDW and the mortar mixes produced.

In this research work the two different sources of CDW, which are most typical in Havana, were treated for the production of fine recycled aggregates and their applicability for masonry mortar was production analyzed. Material taken from both of the CDW sources was submitted to three different crushing processes, which led on to three types

89 of recycled aggregates being produced from each type of CDW under study. The 90 influence of these processes on the properties of the recycled aggregates, and their 91 applicability, in total replacement of natural aggregates, in mortar production were the 
92 main objectives of this research work. Two types of fillers were also used in the 93 manufacturing of the mortar; hydrated lime (recommended by Cuban standard) and 94 limestone filler (widely employed in the city due to its high availability). The physical, 95 mechanical and durability properties of the recycled aggregate mortar mixes were 96 analyzed and their results were compared with those of the results obtained from the 97 analysis of a standard conventional mortar, as well as with the minimum requirements as 98 defined by Cuban specification NC 175:2002 [31] (equivalent to ASTM C270-12 [32]) 99 for type III masonry mortar production.

100

101 2. Materials

$102 \quad 2.1$ Cement

103 An ordinary Portland cement P-350, which according to Cuban standard NC 95:2001 [33], 104 equivalent to ASTM Type I, was employed for all mortar production. It had a density of $1053.12 \mathrm{~g} / \mathrm{cm}^{3}$, specific surface of $3089 \mathrm{~g} / \mathrm{cm}^{2}$ and a compressive strength of $35 \mathrm{MPa}$ at 28 106 days.

$108 \quad 2.2$ Fillers

109 Two different types of fillers were employed for mortar production: lime hydrate (LH) 110 and limestone filler (LF). According to NC 175:2002 [31] the LH which had a dry density 111 and bulk density of $2.1 \mathrm{~kg} / \mathrm{dm}^{3}$ and $0.52 \mathrm{~kg} / \mathrm{dm}^{3}$ respectively, was considered to be an 112 adequate filler for masonry mortar production. The LF, which had a dry density of 2.58 $113 \mathrm{~kg} / \mathrm{dm}^{3}$ and bulk density of $1.14 \mathrm{~kg} / \mathrm{dm}^{3}$, was produced via the grinding of limestone 114 aggregates. LF material is predominantly used within the city of Havana due to the 115 difficulty of obtaining lime hydrate. Fig. 2 illustrates the particle size distribution of both 116 filler materials.

$118 \quad 2.3$ Fine aggregates

119 2.3.1 Production and composition of the recycled fine aggregates

120 The recycled aggregates used in the present work were obtained from two different CDW 121 sources (CDW1 and CDW2). Both types of CDW were representative of the two most 
122 common types of dwellings built in Havana, which date back to the middle of the past

123 century. The CDW1 waste material was obtained from the demolition of buildings with

124 ceramic tiled roofs and compacted earth and limestone walls. In contrast, the CDW2

125 waste was obtained from the demolition of buildings with roofs formed of steel beams

126 and concrete slabs with the walls consisting of ceramic brick. The general composition

127 of the CDW wastes was that of roof and wall elements, however, other materials were

128 also found to be present such as mortar, tiles, etc, which proved to be less than $10 \%$ of

129 the total weight of the whole. An important percentage of the CDW generated in the

130 capital of Havana is produced by the demolition of this type of dwelling [30].

131 The representative sampling was carried out after the crushing of between 3 and 4.5 tons

132 of each of the two types of CDW mentioned and in accordance with BS-EN 932-1:1997

133 regulations [34]. Both types of CDW were individually submitted to three different types

134 of crushing processes for the production of three different kinds of recycled aggregates (-

$135 \mathrm{C},-\mathrm{F}$ and $-\mathrm{CF})$.

136 The process adopted for the obtaining of the first type of fine recycled aggregates (RA1/2-

137 C) was carried out by firstly discarding all material finer than the $4.76 \mathrm{~mm}$ sieve from the

138 total volume of the CDW prior to it passing through the crushing stage. Secondly, the

139 total volume of the material greater than $4.76 \mathrm{~mm}$ was crushed via the employment of a

140 jaw crusher for the production of RA1/2-C fine recycled aggregates [14,29]. For the

141 production of the second type of fine recycled aggregates, RA1/2-F, the CDW material

142 which proved to be finer than the $4.76 \mathrm{~mm}$ sieve was used without undergoing any

143 crushing process. The third and last type of fine recycled aggregates, RA1/2-CF, were

144 obtained via the crushing of the total volume of the CDW to that of a finer material than

$1454.76 \mathrm{~mm}$. In all three types of processes the material finer than $4.76 \mathrm{~mm}$ was separated

146 after every stage of crushing and the remaining fractions found to be coarser than that

147 size were submitted to a new crushing process. The crushing process was completed when

148 all the material accomplishment the desired particle size.

\section{$150 \quad$ 2.3.2 Fine aggregates properties}

151 Raw limestone aggregate obtained from the Arimao quarry which is the highest quality 152 commercialized aggregate in the city [14] was used for the production of the control 153 mortar. 
154 Fig. 3 shows the particle size distribution of all the types of aggregates used in the present 155 study. They were determined following NC 178:2002 [35] specification (equivalent to 156 ASTM C136/C136M-14 [36]). All the recycled aggregates were found to have a similar 157 grading distribution, however when compared to those of the recycled aggregates, the 158 natural aggregates were found to present a lower amount of finer aggregates than 0.297 $159 \mathrm{~mm}$, see Fig. 3. Tests proved that the recycled aggregates not only presented a higher 160 percentage of material finer than $75 \mu \mathrm{m}$, but that they also had lower amounts of passing 161 material through the higher grade sieve than those of the natural aggregates.

162 Table 1 shows the physical properties of the natural and recycled aggregates. The density 163 and water absorption capacity were evaluated according to Cuban standard NC 177:2002 164 [37] (equivalent to ASTM C29/C29M-17 [38] specification). The bulk density and the 165 percentage of the material passing through No. $200(<75 \mu \mathrm{m})$ sieve were determined 166 following NC 181:2002 [39] (equivalent to ASTM C29/C29M-17 [38]) and NC 182:2002 167 [40] (equivalent to ASTM C117-13 [41]) specifications, respectively.

168 The water absorption capacity of all the recycled aggregates proved to be greater than that 169 of the natural aggregate (Table 1), a fact which has also been reported by other researchers $170[13,17-19,22,26,42-44]$. With respect to recycled aggregates, those obtained from 171 crushing the fine and coarse fraction of CDW1 achieved the highest and lowest absorption 172 capacity, respectively. The water absorption capacity of the three recycled aggregates 173 obtained from CDW2 was similar to or higher than that of RA1-C.

174 Table 2 shows the chemical composition of the recycled aggregates, which was 175 determined via Panalytical, Axios PW 4400/40 XRF spectrometers. The calcium and 176 silica content being the main differences between the CDW1 and CDW2 sources. The 177 recycled aggregates produced from the CDW1 source proved to contain approximately $17850 \%$ of silica, as a direct consequence of its high percentage of ceramic material content. 179 The recycled aggregates produced from the CDW2 had a higher composition of calcium, 180 as they originated from concrete elements. The magnesium and aluminum content proved 181 to be the main difference between the composition of the coarse (-C) and fine (-F) fraction. 182 The RA1-F aggregates proved to have a high content of magnesium due to the presence 183 of limestone rocks, as the walls of the dwellings, which formed part of the material 184 sourced for CDW1, had a certain amount of dolomite content in them. In contrast, the 185 RA1-C aggregate proved to have a greater aluminum content, which was a direct result 186 of the influence of the coarse fraction of the ceramic roof material. With respect to the 
187 RA2-F aggregate produced from the CDW2 waste, it was determined that the high 188 magnesium value (limestone-dolomite aggregates were used for concrete production) was 189 a direct result of the high content of material obtained from the concrete roofing. In

190 contrast the RA2-C aggregate, which was obtained from ceramic wall waste, proved to 191 have higher amounts of aluminum content.

\section{3. Mortar Manufacture and Experimental Procedure}

\section{$194 \quad 3.1$ Mortar mixture proportions}

195 Type III Control mortar (bonding and rendering mortar for use at ground level and above) 196 employing natural aggregate, with the volumetric mix proportion of 1:4:2 (cement: 197 aggregate: filler) was produced following NC 175:2002 [31] specifications. This standard 198 recommends the use of lime hydrate as filler. Unfortunately, this is difficult to obtain 199 within Havana and as a consequence the use of limestone filler is also permitted in mortar 200 manufacture. As a direct result of the lack of fine particles within the natural aggregates 201 it is necessary to include filler in the mortar mixture. The mentioned added filler has the 202 effect of reducing the volume of voids within the particle matrix, thus achieving a better 203 performance of the mortars in the fresh and hardened state [45].

204 The 1:5:1 (cement: aggregate: filler) volumetric mix proportion was used for the recycled 205 aggregate mortars production. Prior studies [14] verified that this dosage was the equivalent to the volumetric dosage (1:4:2) established by Cuban regulations for natural 207 aggregates mortars. The higher amount of fine material contained in the recycled 208 aggregate justified the reduction in the use of the filler volume.

209 The manufacturing process was carried out following NC 173:2002 [46] (equivalent to 210 ASTM C348-14 [47] and ASTM C349-14 [48]) specifications. The total water content 211 added to each mortar was determined experimentally in order to obtain a consistency 212 index of $190 \pm 5 \mathrm{~mm}$ in all mortar mixes, and in accordance with Cuban standard NC 213 170:2002 [49] (equivalent to ASTM C1437-15 [50]). The quantity of free water in the 214 paste of each of the mortar mixes defined the effective water cement ratio (see table 3 ). 215 The natural aggregates were used in dry condition while the recycled aggregates were 216 used in wet condition. The effective water absorption capacity of the fine aggregates was 217 determined via soaking them for 30 min (defined by DIN 4226-100 [51]). The method 218 used in the testing was that stipulated by the Cuban regulation NC 186: 2002 [52] 
219 (equivalent to ASTM C 128-97 [53]) for the determination of the $24 \mathrm{~h}$ absorption capacity 220 of natural aggregates. The effective absorption capacity of the recycled and natural 221 aggregates was $80 \%$ and 50\% respectively of their total absorption capacity.

222 Twelve different recycled aggregate mortar mixes were produced, as a result of the 223 combination of the six recycled aggregates (RA1-C, RA1-F, RA1-CF, RA2-C, RA2-F 224 and RA2-CF) with the two fillers (LH, LF). Two control mortars were also manufactured 225 employing natural sand and two types of fillers. Table 3 shows the mix proportions of the 226 mortars.

227 The mortar specimens were de-molded at 24 hours and then, in compliance with 228 regulation NC 173:2002 [46] (equivalent to ASTM C348-14 [47] and ASTM C349-14 229 [48]), cured in a humidity room until the testing stage.

230

$231 \quad 3.2$ Experimental procedure

232 3.2.1. Fresh state test

233 The consistency and water retentivity properties were measured. The consistency of 234 mortar was fixed as $190 \pm 5 \mathrm{~mm}$ for all the mortar mixes in accordance with NC 170:2002 235 [49] (equivalent to ASTM C1437-15 [50]) specifications. The mortar mixes which did 236 not achieve that requirement were rejected.

237 The water retentivity capacity was determined in all of the mortar mixes in accordance 238 with NC 169:2002 [54] (equivalent to ASTM C1506-16b [55]) specifications. The fresh 239 mortar was poured into a $100 \mathrm{~mm}$ diameter cylindrical mould, with a depth of $25 \mathrm{~mm}$, 240 before being subjected to a suction test employing a specific absorption filter. The water 241 retentivity capacity was determined by the amount of water absorbed by the paper filter, 242 being $90 \%$ the minimum value required by Cuban Specification.

244 3.2.2. Hardened state tests

245 Physical (density, absorption and accessible pores) and mechanical (compressive and 246 flexural strength) properties were determined after 28 days of curing according to ASTM 247 C270-12a [32] and NC 173:2002 [46] (equivalent to ASTM C348-14 [47] and ASTM 248 C349-14 [48]) specifications, respectively, employing the Automax compression 249 equipment with $50 \mathrm{kN}$ capacity. 
250 The mortar bond tensile strength was also determined, following the NC 172:2002 [56]

251 specifications. The test, which was carried out over a concrete block surface via the use

252 of a Dyna Haftprufer Pull-off tester Z16 (as described in the previous work [14]), at 28

253 days of curing and in similar conditions to those of the other test specimens.

254 The capillary water absorption capacity of each mortar was also determined after 28 days 255 of curing according to NC 171:2002 [57] (equivalent to ASTM C1403-15 [58]) 256 specifications. All the surfaces of the specimens were sealed with an epoxy resin except 257 for the top and bottom ends of 40 x $40 \mathrm{~mm}$ which were left untreated in order to ensure 258 the one directional transport of the water as described by the regulation.

259 The drying shrinkage was determined according to ASTM C490/C490M-11 [59] 260 specifications. The $25 \times 25 \times 285 \mathrm{~mm}$ mortar specimens, which had been fitted with a 261 stainless steel stud at both ends, were de-molded after 24 hours of casting and kept in an 262 environmental temperature of $28^{\circ} \mathrm{C}$ with a humidity of $80 \%$. The initial length readings 263 were immediately recorded via the use of a length comparator model 62-L0035/A. The 264 length variation was measured over a period of 90 days.

265 The electrical resistivity was determined via the use of a model Vasrmmk11 tester (see 266 Fig. 4). The measurements were taken with the specimens in a saturated condition which 267 was achieved by totally submerging the specimens in water for 24 hours after undergoing 26828 days of curing.

269

270 4. Results and Discussion

\section{$271 \quad$ 4.1 Fresh state properties}

272 4.1.1 Consistency

273 It was necessary to vary the water content employed for the production of the mortars in 274 order to obtain the required consistency of $190 \pm 5 \mathrm{~mm}$. The variation of water content 275 was carried out without using admixtures. Table 3 shows the consistency values obtained 276 by all the mortar mixes produced. The recycled aggregate mortars needed more water 277 than the control mortars in order to achieve the required workability values $(190 \pm 5 \mathrm{~mm})$ 278 established by Cuban regulation NC 170:2002 [49] (equivalent to ASTM C1437-15 [50]).

279 The higher absorption capacity of recycled aggregates with respect to natural aggregates 280 has a negative effect on the consistency of the mortar produced, as the recycled aggregates 
281 absorb part of the mixing water [17,18,60,61]. Additionally, mixtures produced with 282 angular and rough-textured particles, such as those found in recycled aggregates, tend to 283 interlock and reduce inter-particle movement [62].

\section{4.1.2 Water retentivity}

285 The water retentivity results are presented in Table 3. All the mortar mixes (including 286 those produced using recycled aggregate), except for the CM-LF mortar, achieved the 287 minimum value of $90 \%$ required by Cuban specifications. The lower percentage of fine 288 material in the LF filler compared to that of the LH filler (Fig. 2) and the water retaining 289 ability of $\mathrm{LH}$, influenced strongly on this property [63,64]. The recycled aggregate 290 mortars achieved similar or higher water retentivity capacity to that of the control mortar, 291 despite the employment of a lower volume of filler. The finer particle combined with the 292 greater roughness of RA produce a larger specific surface which has the effect of causing 293 a higher amount of water on the surface pores. The result being the creation of a cohesive 294 force, which is prompted by the electrostatic attraction between the positive hydrogen 295 atom and the highly electronegative oxygen atom within a neighboring water molecule 296 (i.e. hydrogen bond) [65]. Neno et al [18] also mentioned that as opposed to sand very 297 fine concrete recycled particles (RCA) must have been retained. The very fine particles 298 of RCA were described as eventually leading on to a filler effect which improved the 299 fresh state. An increase of RCA content within the mortar mixes had the effect of 300 producing a higher water retentivity value.

\subsection{Hardened state properties}

\subsubsection{Physical properties}

304 Table 4 shows the physical properties achieved by all the mortar mixes. The density and 305 absorption capacity of the recycled aggregate mortars was lower and higher, respectively 306 than that of the control mortars. As a result of the mentioned properties of the recycled 307 aggregate [14,18,20,26,65], the mortars manufactured with RA1-F and RA2-F recycled 308 aggregates presented a lower density than the mortars produced employing recycled 309 aggregates obtained via the crushing of the coarser fraction of CDW (RA1-C/-CF and 310 RA2-C/-CF). The mortar produced employing the RAF-1 aggregate achieved the lowest 311 density and highest absorption capacity. The mortar mixes produced employing RA1-F 312 achieved up to $100 \%$ higher absorption capacity than those of the conventional mortars. 
313 A comparative study [19,66] showed that the mortars produced employing recycled 314 aggregates achieved a considerably higher porosity and water absorption capacity value 315 than those of the control mortar. In general, the mortar mixes produced employing LH 316 filler achieved a slightly higher absorption capacity to those of the mortar mixes produced 317 employing the LF filler. The RM1-F-LH and RM1-F-LF mortars achieved values which 318 were twice as great as those of the control mortars.

319 The mortar produced employing RA2-C with LH filler (RM2-C-LH) proved to achieve a 320 higher absorption capacity than the mortar produced employing RA2-F and RA2-CF. The 321 reason for this being its need for a higher water/cement ratio in order to achieve the 322 minimum workability required by Cuban standard.

\subsubsection{Mechanical properties}

325 Figures 5, 6 and 7 show the mechanical property (compressive strength, flexural strength 326 and bond tensile strength, respectively) values of each mortar as well as their 327 corresponding standard deviation.

328 Compressive strength

329 The type III masonry mortar (which is adequate for using at ground level and above, as 330 rendering or bonding material) must have a minimum compressive strength value of 5.2 $331 \mathrm{MPa}$ at 28 days in order to comply with the Cuban standard NC 175:2002 [31]. As shown 332 in Fig. 5, all the mortars achieved the minimum required strength value with the exception 333 of the RM1-F-LF mortar.

334 The recycled mortars achieved a lower compressive strength than those of the 335 conventional mortars, a fact also noted by other researchers[17,67-69]. The mortar mixes 336 produced employing recycled aggregates obtained from the crushing of the coarse type 337 CDW1 (RA1-C) proved to achieve higher strength levels than those produced using the 338 coarse type CDW2 recycled aggregates (RA2-C). The mortars produced employing the 339 RA1-C aggregates achieved a lower than $10 \%$ reduction of compressive strength with 340 respect to that of conventional mortar.

341 The recycled mortars produced employing the aggregates obtained from the fine fraction 342 of the CDW (RA1-F, RA2-F) proved to achieve the lowest strength values. These mortars 343 achieved a reduction in strength value of up to $40 \%$ in the mortars produced with RA1-F 
344 and up to $35 \%$ in the mortars produced with RA2-F. It must be noted that although the 345 four mortars, RM1-F-LH, RM2-F-LH, RM1-F-LF and RM2-F-LF, were produced using

346 a lower w/c ratio to that of the other recycled mortars (in order to obtain adequate 347 workability). A determining factor on the compressive strength of the four mentioned 348 mortars was the poor quality of the recycled aggregates employed in their production. It 349 is known that with respect to conventional mortars the low w/c ratio produces higher 350 strength values. However, this water/cement ratio parameter cannot be considered as an 351 appropriate means of predicting recycled aggregate mortar's strength. This fact has also 352 been noted in other works $[65,70]$.

353 In all cases, the mortar mixes manufactured with LF filler achieved lower compressive 354 strength values than those produced employing LH filler, this was due to its low binder 355 property and coarser fraction. It is known [24] that the improvement of the mechanical 356 strength of the mortars is related to the incorporation of fines within the mortar mixes.

357 Nevertheless, it must be noted that all the mortar mixes manufactured with recycled 358 aggregates obtained by crushing the coarse fraction of the CDW achieved the minimum 359 required values of compressive strength established by Cuban specifications. This 360 denotes the possibility of the total replacement of natural aggregates by those of recycled 361 aggregates with respect to type III mortar production. Certain research $[16,18,26,63]$ also 362 described the possibility of the total substitution of natural aggregate by recycled 363 aggregates for masonry mortar production.

\section{Flexural strength}

365 Flexural strength is not considered a restricted property according to Cuban specification 366 requirements. A comparative study proved that most of the recycled mortars achieved 367 lower flexural strength when compared to natural aggregate mortars, a fact noted by other 368 researchers $[16,42,67,69,71]$. Nevertheless, all the mortars produced employing LH 369 achieved a higher strength value than their corresponding LF mortars. The control and 370 RM1-C-LH mortars produced employing hydrated lime filler achieved the same strength 371 values. The mortars produced employing RA1-F/-CF and RA2-F/-CF achieved lower 372 strength values than those of the mortar mixes produced by employing recycled 373 aggregates obtained solely from the coarse fraction (nominated -C) of CDW (see Fig. 6). 374 The mortars produced employing RA1-F/-CF and RA2-F/-CF with $\mathrm{LH}$ as the filler 375 achieved a reduction of up to $33 \%$ and up to $45 \%$ respectively, with respect to CM-LH. 
376 The mortar produced employing the previous aggregates and LF as a filler achieved a 377 reduction of up to $48 \%$ and $55 \%$ respectively, with respect to the CM-LF mortar.

378 Similarly, with regard to compressive strength values, no relation between the total w/c 379 ratio and the flexural strength of mortars was found. This fact has also been reported in 380 previous works $[16,60]$.

381 According to Vegas et al. [19], Jimenez et al. [20], and Ledesma et al. [15,68], mortars 382 produced employing recycled aggregates of up to $25 \%, 30 \%$ and $40 \%$, respectively, in 383 substitution of natural aggregates obtained similar strength values to those of the control 384 mortars. According to Lopez Gayarre [26] the flexural strength of the recycled aggregate 385 mortar increased with the percentage of recycled ceramic aggregates employed in its 386 manufacture. Neno et al. [18], also related this as happening when employing $100 \%$ of 387 recycled concrete aggregates and verified that this was undoubtedly caused by the 388 reduction that the amount of effective water experienced when the percentage of recycled 389 aggregate for natural aggregate substitution was increased.

\section{Bond tensile strength}

391 According to Cuban regulation NC 175:2002 [31], $0.3 \mathrm{MPa}$ is the minimum bond strength 392 value required for type III masonry mortars. That value could be reduced to $0.2 \mathrm{MPa}$ 393 when the masonry mortars are employed as rendering or bonding for interior walls.

394 Fig. 7 shows the bond strength results obtained by all the mortars as well as the two 395 restrictive values. All the recycled mortars were found to have obtained a lower bond 396 tensile strength than that of the mortars produced employing natural aggregates. The 397 recycled mortars manufactured with aggregates obtained from the CDW-1 source (mainly 398 of ceramic composition), were found to achieve higher bond strength values than the 399 mortars produced with aggregates from the CDW-2 source (heterogeneous source 400 containing mortar, low quality concrete composition and ceramic material). Moreover, 401 the use of recycled aggregates obtained via the crushing of the coarse material within the 402 CDW (RA1-C) achieved the highest property values. According to certain researchers $403[14,16]$, recycled aggregate mortars achieve a lower bond strength capacity than that of 404 control mortars. In contrast, several researchers [42,67,69,72] have determined that 405 mortars produced employing $100 \%$ of recycled aggregate replacement ratio could achieve 406 a higher bond strength values than that of the control mortar. 
407 The use of LF filler in substitution of LH filler caused a reduction of the bond strength,

408 although the highest reduction took place in the mortar produced with natural aggregates.

409 The binder effect of the LH resulted in the increase of the mortars' adhesive capacity [71].

410 The mortars produced employing RA1-F and RA2-F recycled aggregates achieved the 411 lowest bond results. The reduction of bond strength of mortars produced employing LH 412 and LF using RA-F reached levels of up to $45 \%$ and $35 \%$, respectively, with respect to 413 the conventional mortars produced with the corresponding filler.

414 All mortars achieved the 0.2 MPa value established by Cuban standard for rendering 415 mortars which are as suitable for employment on interior walls. However, the RM2-F416 LH, RM1-F-LF and RM2-F-LF mortars, produced employing recycled aggregates RA-F, 417 which were obtained from the fine CDW fraction, did not reach the minimum strength of $418 \quad 0.3 \mathrm{MPa}$ needed for type III masonry mortar.

\subsubsection{Durability properties}

\section{Capillary absorption}

422 Fig. 8 and Fig. 9 indicate the capillary absorption values of the different mortars tested. 423 According to the obtained results, the final capillary absorption value was greatly 424 influenced by the water absorption capacity of the recycled aggregates (see Table 1), a 425 fact which has also been verified by other researchers [18-20,69]. According to Lopez 426 Gayarre et al. [26], the recycled mortar produced with $100 \%$ of ceramic recycled 427 aggregates achieved lower capillary absorption capacity than those of the conventional 428 mortar due to the decrease in the amount of effective water. This decrease being a direct 429 result of an increase in the percentage of the ceramic recycled aggregates employed in the 430 production of the mortar.

431 In this case, all mortars showed similar behavior at 7 hours of testing. However, at 72 432 hours of testing the difference of the high absorption capacity of the recycled aggregates 433 in comparison to those of the natural aggregates was notable. Nevertheless, after 168 434 hours of testing, the mortars produced employing the recycled aggregates with the highest 435 water absorption capacity, RM1-F and RM2-F achieved the highest capillary absorption 436 values. The RM1-C-LH and RM1-CF-LH recycled mortars were the mortars which of all 437 the other recycled mortars obtained the lowest capillary absorption capacity values. 
438 However, these achieved values were higher than those of the conventional mortar CM-

439 LH, which obtained the lowest value.

440 Fig. 8 and Fig. 9 denote the capillary absorption of the mortars produced employing 441 limestone filler (LF), which proved to have a higher capillary absorption capacity in the 442 early stages of testing than those of the mortars produced with hydrated lime (LH). The 443 reason for this difference in capillary absorption was due to the low transfer sorptivity 444 and high water retaining characteristics of hydrated lime [64]. Nevertheless, after 168 445 hours of testing it was determined that the capillary absorption of the mortars depended 446 on the type of aggregates employed in the mortar production and not on the type of filler 447 used. At 168 hours of testing, the capillary absorption values of all the mortars were 448 analyzed. The analysis was carried out by dividing the mortars into in three groups: Group 4491 describes the mortars produced employing the RA1-F recycled aggregate, the RM1-F450 LH and RM1-F-LF mortars, which achieved the highest values; Group 2 describes the 451 behavior of all the other recycled aggregate mortars, which all proved to have achieved 452 similar capillary absorption; Finally, Group 3 describes the control mortars, CM-LF and 453 CM-LH, which achieved the lowest capillary absorption values of all the mortars tested.

454 The capillary absorption values of the mortars from group 1, 2 and 3 were 6,5 and 4 $455 \mathrm{~g} / \mathrm{cm}^{2}$ at $168 \mathrm{~h}$, respectively. The test results imply that the final value of the capillary 456 absorption (at $168 \mathrm{~h}$ ) depended directly on the water absorption of the recycled aggregate 457 which was employed in the mortar manufacture [60,63]. There was no significant 458 difference noted on the capillary absorption values when LH or LF filler was employed 459 for mortar production.

460 Drying shrinkage

461 The mortars produced employing recycled aggregates suffered a higher shrinkage than 462 the mortars manufactured employing natural aggregates (see Fig. 10 and Fig. 11). This 463 was due to their greater water absorption capacity. This difference in levels of shrinkage 464 has also been described by several researchers [16,18,68,73].

465 Silva et al. [61], found that mortars employing 20\%, 50\% and $100 \%$ of ceramic recycled 466 aggregates achieved similar shrinkage values amongst themselves, but those values were 467 higher than those obtained by the control mortar. According to Vegas et al. [19], Cabrera468 Covarrubias et al. [74], Jimenez et al [20], and Lopez Gayarre et al. [26] the mortar 469 produced employing up to $25 \%, 30 \%, 40 \%$, and $50 \%$ respectively, of ceramic aggregates 
470 achieved acceptable shrinkage values when compared to the same values obtained by 471 conventional mortars.

472 Although the mortars produced using LH filler proved to have higher shrinkage values 473 than those of the mortars manufactured with limestone filler (LF), they were found to 474 achieve the minimum required workability using less water content than the mortars 475 incorporating LF. A comparative study between the LH filler and the LF filler showed 476 that the higher quantity of material finer than $75 \mu \mathrm{m}$ in the LH filler and its water retaining 477 capacity proved to have a great influence on the increase of the shrinkage value. This fact 478 has also been described by other researchers [70,75].

479 All the recycled mortars produced using LF filler achieved similar shrinkage values in 480 spite of the different composition and properties of the recycled aggregates employed. 481 According to Miranda and Selmo [75], the use of different percentages of recycled 482 aggregates was influential on the mortars' shrinkage but not on their composition.

483 Electrical resistivity

484 Fig. 12 indicates the electrical resistivity values of all the studied mortars. All the mortars 485 achieved a low resistivity value as a result of their high absorption capacity and low 486 mechanical properties. However, all the recycled mortars, with the exception of those 487 mortars produced employing RA1-F and RA2-F aggregates, achieved a higher resistivity 488 level than those of the control mortars.

489 In all probability, the presence of ceramic material in the recycled aggregates explains the 490 higher value achievement of the recycled mortars when compared to the same values 491 obtained from the control mortars. Similar results to those exposed have been reported in 492 a previous study [14]. The coarse fraction of the CDW contained a higher percentage of 493 ceramic material than the fine fraction. CDW-1 proved to have the highest amount of this 494 ceramic material, and it was this ceramic content which caused the highest electrical 495 resistivity levels in these mortars due to its inherent electrical insulating properties. 496 Consequently, the property of electrical resistivity is not an adequate form of assessing 497 the quality of mixed recycled aggregates mortars, as the values reported are more affected 498 by the content of siliceous material than by the saturated porous ramification. 


\section{Conclusions}

501 The following conclusions and recommendations for the use of RA and filler in masonry

502 mortar can be drawn from the results of this study:

503 Recycled aggregates:

504

- For the adequate quality of the RA1 recycled aggregates production, a coarse fraction $(>4.76 \mathrm{~mm})$ of the CDW1 is required. Taking into consideration in this study that the main component of the CDW1 was ceramic, with soil and limestone as the finest materials and minor components and with the complete absence of concrete.

- When the main component of the CDW is concrete combined with a low amount of impurities, the recycled aggregate produced employing only the fine fraction of CDW $(<4.76 \mathrm{~mm})$ achieved similar properties to those produced crushing the coarse fraction of CDW.

Fresh state of recycled aggregate mortars:

Hardened state of recycled aggregate mortars:

520

- The use of recycled aggregates produced from the fine fraction of CDW1, which was mainly composed of earth and limestone, increased the mortars' absorption capacity of up to $100 \%$ with respect to that of conventional mortar. Consequently, it was necessary to employ the ceramic material presented in the coarse fraction of CDW for recycled aggregate production.

- Whereas the mortars produced employing recycled aggregate obtained from the CDW1, which had ceramic as its main component, achieved similar mechanical properties to conventional mortar, it was discovered that the use of the recycled aggregates obtained from CDW2 (concrete with main component) achieved lower properties than those of conventional one. 
530

- The employment of LH filler as opposed to LF can result in 50\% higher strength mortars than those of mortars made with LF employing the same type of recycled aggregates.

- Although recycled aggregate mortars achieved a higher shrinkage value than that of conventional mortars, the employment of LF filler in recycled aggregate mortars reduced the shrinkage achieved by mortars produced with LH by up to $25 \%$.

The recycled aggregates produced from the CDW composed of ceramic materials achieved the best properties and were found to be able to produce recycled mortars with adequate properties. However, in order to comply with the minimum quality requirements established for recycled aggregate mortars, it is necessary to employ the coarse fraction of the CDW in recycled aggregate production. Test results of the RA-F (recycled aggregates produced using only the fine fraction of CDW) determined that it was only adequate for the rendering or bonding of interior walls at or above ground level.

Although the mortars produced employing hydrated lime achieved higher mechanical properties than those of the mortars produced using limestone filler, it was established that both, the physical properties and the shrinkage values, of the mortars produced employing the limestone filler were more adequate. A finer grading distribution of the limestone filler (only $40 \%$ of the available LF is finer than $75 \mu \mathrm{m}$ ) could be responsible for improving both the retentivity and the mechanical properties of the mortars assuring a general improvement of properties of masonry recycled mortars.

\section{Acknowledgements}

The authors would like to thank the Spanish Agency of International Cooperation for Development (AECID) and The Ministry of Exterior Affairs and Cooperation for the financial support given to the above research work. The authors also thank the GREAT project code PIRSES-GA-2013-612665 for financial support.

\section{Reference}

[1] J.S. Damtoft, J. Lukasik, D. Herfort, D. Sorrentino, E.M. Gartner, Sustainable development and climate change initiatives, Cem. Concr. Res. 38 (2008) 115-127. 
doi:10.1016/j.cemconres.2007.09.008.

H. Yuan, L. Shen, Trend of the research on construction and demolition waste

management,

Waste

Manag.

31

(2011)

$670-679$.

doi:10.1016/j.wasman.2010.10.030.

565

[3] N. Kisku, H. Joshi, M. Ansari, Panda S K, Sanket Nayak, Sekhar Chandra Dutta, 566

567

568

569

[4]

A critical review and assessment for usage of recycled aggregate as sustainable construction material, Constr. Build. Mater. 131 (2017) 721-740. doi:10.1016/J.CONBUILDMAT.2016.11.029.

570

571

572

[5] Waste Manag. 60 (2017) 277-289. doi:10.1016/J.WASMAN.2016.08.011.

573

574

575

576

[6]

A. Ossa, J.L. García, E. Botero, Use of recycled construction and demolition waste (CDW) aggregates: A sustainable alternative for the pavement construction industry, J. Clean. Prod. $135 \quad$ (2016) 379-386. doi:10.1016/J.JCLEPRO.2016.06.088.

M.D. Bovea, J.C. Powell, Developments in life cycle assessment applied to evaluate the environmental performance of construction and demolition wastes, Waste Manag. 50 (2016) 151-172. doi:10.1016/J.WASMAN.2016.01.036.

R.V. Silva, J. de Brito, R.K. Dhir, The influence of the use of recycled aggregates on the compressive strength of concrete: a review, Eur. J. Environ. Civ. Eng. 19 (2015) 825-849. doi:10.1080/19648189.2014.974831.

[11] M.M. Tüfekçi, Ö. Çakir, An Investigation on Mechanical and Physical Properties of Recycled Coarse Aggregate (RCA) Concrete with GGBFS, Int. J. Civ. Eng. 15 (2017) 549-563. doi:10.1007/s40999-017-0167-x.

[12] Y.-J. Fan, B.-S. Yu, S.-L. Wang, Analysis and Evaluation of the Stochastic Damage for Recycled Aggregate Concrete Frames Under Seismic Action, Int. J. 
Civ. Eng. (2017). doi:10.1007/s40999-017-0203-X.

596 [13] L. Restuccia, C. Spoto, G. Andrea Ferro, J.-M. Tulliani, Recycled Mortars with 597 C\&D Waste, Procedia Struct. Integr. 2 (2016) 2896-2904. doi:10.1016/j.prostr.2016.06.362.

[14] I. Martínez, M. Etxeberria, E. Pavón, N. Díaz, A comparative analysis of the properties of recycled and natural aggregate in masonry mortars, Constr. Build. Mater. 49 (2013) 384-392. doi:10.1016/j.conbuildmat.2013.08.049.

[15] E.F. Ledesma, J.R. Jiménez, J.M. Fernández, a. P. Galvín, F. Agrela, a. Barbudo, Properties of masonry mortars manufactured with fine recycled concrete aggregates, Constr. Build. Mater. 71 (2014) 289-298. doi:10.1016/j.conbuildmat.2014.08.080.

[16] P. Saiz Martínez, M. González Cortina, F. Fernández Martínez, A. Rodríguez Sánchez, Comparative study of three types of fine recycled aggregates from construction and demolition waste (CDW), and their use in masonry mortar fabrication, J. Clean. Prod. $118 \quad$ (2016) 162-169. doi:10.1016/j.jclepro.2016.01.059.

[17] Z. Zhao, S. Remond, D. Damidot, W. Xu, Influence of fine recycled concrete aggregates on the properties of mortars, Constr. Build. Mater. 81 (2015) 179-186. doi:10.1016/j.conbuildmat.2008.06.007.

[18] C. Neno, J. De Brito, R. Veiga, Using fine recycled concrete aggregate for mortar production, Mater. Res. 17 (2014) 168-177. doi:http://dx.doi.org/10.1590/S151614392013005000164.

[19] I. Vegas, I. Azkarate, A. Juarrero, M. Frías, Design and performance of masonry mortars made with recycled concrete aggregates, Mater. Construcción. 59 (2009) 5-18. doi:10.3989/mc.2009.44207.

[20] J.R. Jiménez, J. Ayuso, M. López, J.M. Fernández, J. De Brito, Use of fine recycled aggregates from ceramic waste in masonry mortar manufacturing, Constr. Build. Mater. 40 (2013) 679-690. doi:10.1016/j.conbuildmat.2012.11.036.

[21] E. Dapena, P. Alaejos, a. Lobet, D. Pérez, Effect of Recycled Sand Content on Characteristics of Mortars and Concretes, J. Mater. Civ. Eng. 23 (2011) 414-422. doi:10.1061/(ASCE)MT.1943-5533.0000183.

[22] F.G. Cabrera-Covarrubias, J.M. Gómez-Soberón, J.L. Almaral-Sánchez, S.P. Arredondo-Rea, M.C. Gómez-Soberón, R. Corral-Higuera, An experimental study of mortars with recycled ceramic aggregates: Deduction and prediction of the 
stress-strain, Materials (Basel). 9 (2016). doi:10.3390/ma9121029.

630 [23] J. Silva, J. de Brito, R. Veiga, Incorporation of fine ceramics in mortars, Constr. Build. Mater. 23 (2009) 556-564. doi:10.1016/j.conbuildmat.2007.10.014.

[24] M. Braga, J. De Brito, R. Veiga, Incorporation of fine concrete aggregates in mortars, Constr. Build. Mater. $36 \quad$ (2012) 960-968. doi:10.1016/j.conbuildmat.2012.06.031.

[25] W. Jackiewicz-Rek, K. Załęgowski, A. Garbacz, B. Bissonnette, Properties of Cement Mortars Modified with Ceramic Waste Fillers, Procedia Eng. 108 (2015) 681-687. doi:10.1016/j.proeng.2015.06.199.

[26] F. López Gayarre, Í. López Boadella, C. López-Colina Pérez, M. Serrano López, A. Domingo Cabo, Influence of the ceramic recycled agreggates in the masonry mortars properties, Constr. Build. Mater. 132 (2017) 457-461. doi:10.1016/j.conbuildmat.2016.12.021.

[27] C. Ulsen, H. Kahn, G. Hawlitschek, E.A. Masini, S.C. Angulo, V.M. John, Production of recycled sand from construction and demolition waste, Constr. Build. Mater. 40 (2013) 1168-1173. doi:10.1016/j.conbuildmat.2012.02.004.

[28] H. McWilliams, C.T. Griffin, A critical assessment of concrete and masonry structures for reconstruction after seismic events in developing countries, in: P. Cruz (Ed.), Struct. Archit. Concepts, Appl. Challenges, CRC Press, Boca Raton, 2013: pp. 857-864.

[29] E. Pavón, I. Martínez, M. Etxeberria, The production of construction and demolition waste material and the use of recycled aggregates in Havana, Cuba, Rev. Fac. Ing. (2014) 167-178. http://aprendeenlinea.udea.edu.co/revistas/index.php/ingenieria/article/view/1551 6.

[30] I. Muñoz Fernández, Estudio económico y ambiental del cambio de la gestión de residuos de construcción y demolición en la ciudad de La Habana, Master Thesis directed by Miren Etxeberria \& Alvar Garola, Universidad Politécnica de Cataluña (UPC), 2012, http://upcommons.upc.edu/handle/2099.1/14827.

[31] NC 175: 2002, Morteros de albañilería. Especificaciones, Cuba, 2002.

[32] ASTM C 270-12a, Standard Specifications for Mortars for Unit Masonry, USA, 2012.

[33] NC 95: 2001, Cemento Portland. Especificaciones, Cuba, 2001.

[34] BS EN 932-1:1997, Tests for general properties of aggregates. Methods for 
663

664

665

666

667

668

669

670

671

672

673

674

675

676

677

678

679

680

681

682

683

684

685

686

687

688

689

690

691

692

693

694

695

696

sampling, 1997.

[35] NC 178: 2002, Áridos. Análisis granulométrico, Cuba, 2002.

[36] ASTM C136/136M-14, Standard Test Method for Sieve Analysis of Fine and Coarse Aggregates, USA, 2014.

[37] NC 177: 2002, Áridos. Determinación del porciento de huecos, Cuba, 2002.

[38] ASTM C29/C29M-17, Standard Test Method for Bulk Density ("Unit Weight”) and Voids in Aggregate, American Society for Testing and Materials, USA, 2017.

[39] NC 181: 2002, Áridos. Determinación del peso volumétrico, Cuba, 2002.

[40] NC 182: 2002, Áridos. Determinación del material más fino que el tamiz de $0.074 \mathrm{~mm}$, Cuba, 2002.

[41] ASTM C117-13, Standard Test Method for Materials Finer than 75- $\mu$ m (No. 200) Sieve in Mineral Aggregates by Washing, American Society for Testing and Materials, USA, 2013.

[42] V. Corinaldesi, G. Moriconi, Behaviour of cementitious mortars containing different kinds of recycled aggregate, Constr. Build. Mater. 23 (2009) 289-294. doi:10.1016/j.conbuildmat.2007.12.006.

[43] L. Evangelista, J. De Brito, Durability performance of concrete made with fine recycled concrete aggregates, Cem. Concr. Compos. 32 (2010) 9-14. doi:10.1016/j.cemconcomp.2009.09.005.

[44] L. Evangelista, M. Guedes, J. de Brito, a. C. Ferro, M.F. Pereira, Physical, chemical and mineralogical properties of fine recycled aggregates made from concrete waste, Constr. Build. Mater. 86 (2015) 178-188. doi:10.1016/j.conbuildmat.2015.03.112.

[45] A.K.H. Kwan, M. McKinley, Effects of limestone fines on water film thickness, paste film thickness and performance of mortar, Powder Technol. 261 (2014) 3341. doi:10.1016/J.POWTEC.2014.04.027.

[46] NC 173: 2002, Mortero endurecido. Determinación de la resistencia a flexión y compresión, 2002.

[47] ASTM C348-14, Standard Test Method for Flexural Strength of Hydraulic-Cement Mortars, American Society for Testing and Materials, USA, 2014.

[48] ASTM C349-14, Standard Test Method for Compressive Strength of HydraulicCement Mortars (Using Portions of Prisms Broken in Flexure), American Society for Testing and Materials, USA, 2014.

[49] NC 170: 2002, Mortero fresco. Determinación de la consistencia en la mesa de 
697

698

699

700

701

702

703

704

705

706

707

708

709

710

711

712

713

714

715

716

717

718

719

720

721

722

723

724

725

726

727

728

729

730

sacudidas, 2002.

[50] ASTM C1437-15, Standard Test Method for Flow of Hydraulic Cement Mortar, American Society for Testing and Materials, USA, 2015.

[51] DIN 4226-100:2002-02, Aggregates for concrete and mortar - Part 100: Recycled aggregates, Germany, 2002.

[52] NC 186: 2002, Arena. Peso específico y absorción de agua, Cuba, 2002.

[53] ASTM C128-97, Test Method for Specific Gravity and Absorption of Fine Aggregate, American Society for Testing and Materials, USA, 1997.

[54] NC 169: 2002, Mortero fresco. Determinación de la capacidad de retención de agua, Cuba, 2002.

[55] ASTM C1506-16b, Standard Test Method for Water Retention of Hydraulic Cement-Based Mortars and Plasters, American Society for Testing and Materials, USA, 2016.

[56] NC 172: 2002, Mortero endurecido. Determinación de la resistencia a la adherencia por tracción, 2002.

[57] NC 171: 2002, Mortero endurecido. Determinación de la absorción de agua por capilaridad, 2002.

[58] ASTM C1403-15, Standard Test Method for Rate of Water Absorption of Masonry Mortars, American Society for Testing and Materials, USA, 2015.

[59] ASTM C490/C490M-11, Standard Practice for Use of Apparatus for the Determination of Length Change of Hardened Cement Paste, Mortar, and Concrete, American Society for Testing and Materials, USA, 2011.

[60] G.M. Cuenca-Moyano, M. Martín-Morales, I. Valverde-Palacios, I. ValverdeEspinosa, M. Zamorano, Influence of pre-soaked recycled fine aggregate on the properties of masonry mortar, Constr. Build. Mater. 70 (2014) 71-79. doi:10.1016/j.conbuildmat.2014.07.098.

[61] J. Silva, J. de Brito, R. Veiga, Recycled Red-Clay Ceramic Construction and Demolition Waste for Mortars Production, J. Mater. Civ. Eng. 22 (2010) 236-244. doi:10.1061/(ASCE)0899-1561(2010)22:3(236).

[62] G.S. Wong, A.M. Alexander, R. Haskins, T.S. Poole, P.G. Malone, L. Wakeley, Portland-cement concrete rheology and workability: final report, McLean: US Department of Transportation and Office of Infrastructure Research and Development, 2001. 
masonry mortars containing recycled aggregates from construction and demolition wastes, Constr. Build. Mater. 105 (2016) 400-415. doi:10.1016/j.conbuildmat.2015.12.171.

[64] C. Ince, S. Derogar, N.Y. Tiyakioglu, Y.C. Toklu, The influence of zeolite and

[68] E.F. Ledesma, J.R. Jiménez, J. Ayuso, J.M. Fernández, J. de Brito, Maximum feasible use of recycled sand from construction and demolition waste for ecomortar production - Part-I: ceramic masonry waste, J. Clean. Prod. 87 (2015) 692706. doi:10.1016/j.jclepro.2014.10.084.

[69] S.-C. Kou, C.-S. Poon, Effects of different kinds of recycled fine aggregate on properties of rendering mortar, J. Sustain. Cem. Mater. 2 (2013) 43-57. doi:http://dx.doi.org/10.1080/21650373.2013.766400.

[70] M. Braga, J. Brito, R. Veiga, Reduction of the cement content in mortars made with fine concrete aggregates, Mater. Struct. 47 (2014) 171-182. doi:10.1617/s11527-013-0053-1.

[71] M. Stefanidou, E. Anastasiou, K. Georgiadis Filikas, Recycled sand in lime-based mortars, Waste Manag. 34 (2014) 2595-2602. doi:10.1016/j.wasman.2014.09.005.

[72] V. Corinaldesi, Mechanical behavior of masonry assemblages manufactured with recycled-aggregate mortars, Cem. Concr. Compos. 31 (2009) 505-510. doi:10.1016/j.cemconcomp.2009.05.003.

[73] H.. Mesbah, F. Buyle-Bodin, Efficiency of polypropylene and metallic fibres on control of shrinkage and cracking of recycled aggregate mortars, Constr. Build. Mater. 13 (1999) 439-447. doi:10.1016/S0950-0618(99)00047-1. 
765 [74] F.G. Cabrera-Covarrubias, J.M. Gómez-Soberón, J.L. Almaral-Sánchez, S.P. 766 Arredondo-Rea, R. Corral-Higuera, Mechanical properties of mortars containing 767 recycled ceramic as a fine aggregate replacement, Rev. La Constr. 14 (2015) 2276829.

769 [75] L. Miranda, S. Selmo, CDW recycled aggregate renderings : Part I - Analysis of 770 the effect of materials finer than $75 \mathrm{~lm}$ on mortar properties, Constr. Build. Mater. 771 (2006) 615-624. doi:10.1016/j.conbuildmat.2005.02.025. 


\section{Influence of demolition waste fine particles on the properties of recycled aggregate} masonry mortar

\section{Iván Martínez a , Miren Etxeberria ${ }^{\text {b,*, }}$ Elier Pavón c, Nelson Díaz ${ }^{\text {d }}$}

a MSc Student, Eng. Instituto de Ingeniería, UNAM, Circuito Escolar sn, Ciudad Universitaria, 04510, Mexico City, Mexico. Tel: +52 56233600. Email: IMartinezH@iingen.unam.mx

b Associate Professor, Dr. Eng. Department of Civil and Environmental Engineering, Universidad Politécnica de Cataluña, Barcelona, Spain. Tel: +34 934011788. Email: miren.etxeberria@upc.edu

${ }^{c}$ Assistant Professor, MSc. Centro das Ciências Exatas e das Tecnologias, Universidade Federal do Oeste da Bahia, Rua Professor Jose Seabra de Lemos, 316. Recanto dos Passaros, CP 47808-021, Barreiras, Bahia, Brasil. Tel: +55 7736143116. Email: elierpavon@ufob.edu.br

d Associate Professor, MSc. Departamento de Construcciones, Universidad Tecnológica de La Habana José Antonio Echeverría, Calle 114, 11901 e/ Ciclovia y Rotonda, Marianao, Havana City, Cuba. Tel: +53 72663000, Fax:+5372663827. Email: nediaz@civil.cujae.edu.cu

* Corresponding author

Funder: Ministerio de asuntos Exteriores (ES). Award number: A1/038206/11.

Recipient: Dr. Miren Etxeberria 


\section{ANSWER TO REVIEWERS}

All the comments given by reviewers have been carried out.

\section{REVIEWER \#4:}

Some arguments and improvements have been fixed. Others persist and are not properly solved. Again they are indicated and more arguments detail them. The reviewer has requested these improvements since the first review (February / 2017, 7 months), the only arguments that the authors provide are: The authors consider that they are not necessary and the authors have performed the tests that are technically used to apply this material. I remind the authors that to publish in this "Scientific Journal" necessarily means to carry out a scientific work with demonstrations, laboratory tests and specific tests that guarantee and explain the exposed behaviors. Without this, the work is a simple laboratory report.

The authors consider that this paper is interesting, it describes many tests and analyzed scientifically the results values. The obtained results have been discussed with respect to the chemical, physical and mechanical properties achieved by the raw recycled materials as well as comparing the obtained results to those achieved by other authors.

\section{COMMENTS TO BE SOVED:}

- 14 (important, please provide experimental or documentary evidence of the comments, not assumptions).

This comment had been done in the previous reviews: "Without the statistical validation of the data, or in the absence of the EXACT quantification of the parameters involved in the experiment, unable to validate the scientific contribution (it is a particular case of study and the variables interfering have not been established or determined). There are substances potentially polluting or affecting the behavior of mortars that "could" be included in the "random" samples studied (gypsum, paint, organic, wood, asphalt, metals, etc., etc.); for which, it is necessary (and obliged) to include tests that show its absence or presence (and its quantification in quantity). Without this information (statistical or of tests) ALL the research does not have a valid sustenance.")

\section{Answer 14:}

The dispersion of the obtained values (of mechanical properties) are given in the figures. The authors do not consider that more detailed statistical data are necessary due to:

- The presence of paint is irrelevant in all cases, it is not even measurable in terms of percent of weight. In addition, the gypsum was not employed as construction 
material in demolished building. Furthermore, as Table 2 shows, the sulfate amount is negligible. The chemical composition of all the types of recycled aggregates are described in table 2 in the section 2.3 "Fine aggregates".

- The samples of CDW were collected on the demolition site, making the collection under good control. Consequently, none of the other polluting substance could be included. In addition, the CDW has been added manually to crushing process, in consequence avoiding the inclusion of this polluted substances. Furthermore, Table 2 shows that the sulfate amount is negligible.

- 21 (is obliged to do so, please provide experimental or documentary evidence of the comments, not assumptions. Perform laboratory tests).

This comment had been made in the previous reviews: "What procedure, technique, standards, equipment, instruments, etc., etc., were used to obtain the data of the Table 5? Is necessary that is contribution information of the existence of more compounds with possible involvement in the behavior of the mortars: chlorides, sulfates, gypsum, metals, organic, etc., etc. It is requested to use precision techniques such as XRD or FTNIR."

\section{Answer 21:}

Table 5 now is named Table 2.

The composition of aggregates were determined via Panalytical, Axios PW 4400/40 $\mathrm{XRF}$ spectrometers. In this case, the chemical composition was required to determine, however the crystallography which could be determined via XRD would not give any additional information, since their chemical composition and components are known. As it was mentioned above, the samplings were collected manually from the demolition site and the external contaminations were not present in the material. Moreover, the addition of the material to the crusher was also made manually.

- $\underline{\mathbf{2 5}}$ (please indicate the sequence and mixing times, initial and final water). This comment had been made in the previous reviews: "It is necessary to indicate the process of mixture used, since the recycled aggregates have a high absorption; If it was not considered, will provoke that the free water for hydration is not adequate one, and therefore the behavior of mortars in hardened phase is affected."

\section{Answer 25:}

The manufacturing process of mortars is indicated in the section 3.1 and was carried out following the corresponding ASTM and Cuban standards. The total water used in the mortar production was the added water required in order to get adequate workability in each mortar.

As it is exposed in the section 3.1, even with the high water absorption of the recycled aggregates, the effective w/c ratio of those mortars was very high (see table 3 ). This has a negative influence over the hardened state properties, but in masonry mortars 
admixtures are rarely used. As a consequence, in order to achieve the required workability, a high w/c proportion is necessary.

- 27 (please perform ALL TESTING and TESTS, including NON-STANDARDS). This comment had been made in the previous reviews: "It is necessary to indicate the brand, model and place of manufacture of all the equipment used in the tests."

Answer 27:

All test and equipment used are indicated in the text since the first revision.

- 28 (important. Please include the requested tests, it is not a laboratory report for validity "an application", it is a "scientific research". It is necessary to carry out the tests that have been requested.).

This comment had been made in the previous reviews: "Why was not obtained the density in fresh, the air content and some another test of fluency of the mixtures? It is requested to include them.".

Answer 28:

The authors think that the asked tests are not relevant for the study. The fresh state tests of consistency and water retentivity were determined, which were required by standards and values defined by references. The physical properties of density and absorption capacity were determined in hardened state of masonry mortars. Most of the tests described by the reviewer are not included in the papers used as references.

- 37 (is obliged to do so, please perform the experimental tests and laboratory tests requested).

This comment had been made in the previous reviews: "It is necessary that the authors rewrite this section, improving their wording and arguing the cause that makes evident the differences between mortars; For which it is necessary to carry out specific tests that allow a correct explanation. The authors are asked to characterize the matrix of the mortars, identification of the ITZ and study of the porous network (SEM tests and mercury porosimetry)".

\section{Answer 37:}

The obtained results have been discussed according to the previous works done by several author. Since the samples had a very high water/cement ratio and in consequence a high amount of accessible porous and absorption capacity, the physical properties determined in this paper (table 4) give enough details and properties to make an appropriate comparison. 
- $\underline{\mathbf{4 0}}$ (as the reviewer-number 1 also comments, writing needs to be improved. Again, the authors try to publish in a scientific Journal, NOT validating an application of a material. To publish in this Scientific Journal it is necessary to carry out an investigation that explains the behavior of this material. Please carry out the requested tests). This comment had been made in the previous reviews: "Authors are requested to be accurate in their comments: ... in all probability due to its low binder...

It is necessary to include a study of the matrix of the mortars that allows to explain the described behaviors; Otherwise, this work does not solve or explain the results indicated.

“

Answer 40:

The authors think that the writing is concise. All the tests (physical, mechanical and durability properties ) required by the standards for masonry mortars were carried out and the obtained results by recycled aggregate mortars were compared to those of conventional mortar as well as the required values defied by standards and scientific references, which gave us the most valuable parameter.

- $\underline{43}$ (is obliged to do so, please do the tests requested, without these you can not prove what you say).

This comment had been made in the previous reviews:

\section{"Durability properties}

Capillary absorption

It is necessary to include studies of the porous network of mortars (porosimetry with mercury), which allow to EXPLAIN the values included in this research. The authors have limited themselves to performing just one description of the values."

\section{Answer 43:}

The $\%$ of accessible porous, the effective w/c ratio and the absorption capacity of recycled aggregates were measured and known. The authors consider that for the objective of the paper, the MIP test cannot give more valuable properties than the values already described, due to the high w/c ratio and high porosity of masonry mortars. Moreover, there is very hard to find a single paper where MIP measurements are used, including the papers which have been recommend by the reviewer to be consider in this paper.

The determined properties influence considerably at the capillary absorption capacity. So, the authors think that the capillary absorption graphs and the sorptivity coefficient value describe adequately the different behaviors of those masonry mortars.

- 45 (important, please carry out the tests with the detail that was requested). 
This comment had been made in the previous reviews: "It is necessary that the work distinguish total shrinkage, drying shrinkage and basic shrinkage.

It is necessary to indicate the standard that was used and the instruments (marks, models, precision, etc.)"

Answer 45:

The drying shrinkage was determined according to ASTM C490/C490M-11 [59] specifications. (see section 3.2.2. Hardened state tests). As the high amount of water has been used for mortars production, the drying shrinkage is the most important shrinkage to be considered.

- 47 (please perform the tests, so the arguments given are based on facts and not on assumptions; comments that the authors make)

This comment had been sent in the previous reviews: "Given the type of aggregates used and the possibility of containing materials that affect the durability of mortars, it is necessary to include leaching tests and accelerated expansion studies."

Answer 47:

As the recycled aggregates have not been contaminated, it is explain above (see Comment/answer14), the hazard leached components was expected to be lower than the limit specify by standards, considering an inert material. There were not metals either gypsum present at the CDW.

- $\underline{49}$ (please indicate in the text to publish the indicated reasons).

This comment had been sent in the previous reviews:" Reference Authors are requested to:

1) Reflect on the reason why these two works "owned by the same authors" have not been cited.

2) Explain what new or new contribution has the current proposal of work that is not included in these references "omitted".

The authors think that is not appropriate to indicate in the text the difference between this work and other(s) previous work(s) carried out by the authors.

1) The previous papers of the authors have been referenced in order to avoid some details that had been already published in previous papers and they were necessary to describe. One of the reference [23] has been removed, since the authors considered that it was very difficult to find it by the reader.

2) The objective of this paper was to analyze the influence of the fine particles $(<4.76 \mathrm{~mm})$ within the construction and demolition waste obtained from dwellings in 
Havana on the properties of the recycled aggregates obtained from that source. The RA was to be used together with two types of fillers (limestone or hydrated lime) for the production of type III masonry mortars and their respective qualities were to be analyzed. From both types of the CDW used, three types of recycled aggregates were to be produced (-F, CF, and $-\mathrm{C})$. The six types of recycled aggregates were to be mixed with two types of fillers for the production of masonry mortars. In the previous paper "MARTINEZ, Iván; ETXEBERRIA, Miren; PAVON, Elier y DIAZ, Nelson. Analysis of the properties of masonry mortars made with recycled fine aggregates for use as a new building material in Cuba. Revista de la Construcción [online]. 2016, vol.15, n.1, pp.921. ISSN 0718-915X', only one type of recycled aggregate was produced of each type of CDW. In addition, for recycled mortar production also only one type of filler was employed. The main objective of the previous paper was to determine, according to the grading distribution of recycled aggregates, the optimum mix proportion for recycled masonry mortar production, in order to be used as a bond and rendering mortar. For that purpose, different cement/aggregate/filler proportions were employed for mortar production. While in the previous work only one type of recycled aggregate was produced from each type of CDW and one type of filler was used for mortar production, in this research work 3 types of recycled aggregates were produced from each CDW and two types of fillers were employed. In addition, although in this work the optimum mix proportion defined in the previous work has been used, that it is not the case with the recycled aggregates production, their characteristics and the type of filler employed were different to the prior work and the influence of those parameters on the properties of masonry mortars are important and were assessed in this new work.

\section{NOTES:}

The reviewer maintains the following comment, HAS NOT BEEN SOLVED PROPERLY:

Figure 2 and 3, curves outside the graph.

The authors had corrected this error in the previous review.

The given answered was: "Figure 2 and Figure 3 have been modified. The previous error was just due to the type of graphic employed for drawing. "

Images should be enhanced in editing and provide information with labels.

All the figures fulfill the IJCE specifications.

The reviewer maintains the following comment, HAS NOT BEEN SOLVED PROPERLY (the reviewer disagrees in the comment; you can use different colors, textures and graphics). Having the graphics together simplifies the work and allows other researchers to have a joint view of the study. 
Do you consider that the union in a single graph of Figures 5, 6 and 7 would be better to reach a joint compression of the behavior of the mortar?

The authors think that it is better not to join the three figures. The values of each property are very difference in magnitude between them, and there are 14 columns in each graph. In addition, the limited value described by Cuban specifications are also included in each figure.

The reviewer maintains this request, that the document is a public document does not grant automatically or necessarily the scientific value and rigor. It needs to be reviewed by experts in this field before granting complete credibility.

Inadequate reference for a scientific article:

[30] Ingrid Muñoz, "Estudio económico y ambiental del cambio de la gestión de residuos de construcción y demolición en la ciudad de La Habana", Master thesis directed by Miren Etxeberria \& Alvar Garola Universidad Politécnica de Cataluña, 2012. https://upcommons.upc.edu/handle/2099.1/14827

The authors consider that the reference is adequate as it shows the real data of $\mathrm{La}$ Habana, it is a extend work and it is validated by professor of CUJAE.

\section{REVIEWER \# 1}

$\underline{\mathbf{- 1}}$ The highlights are still not very different from the abstract.

Answer 1:

The highlights have been rewritten.

-2. There is no mention of loss of prestress. Justify.

Answer 2:

The loss of mechanical properties of recycled aggregate mortars with respect to conventional control is due to the low quality of recycled aggregates.

It is explained in section "4.2.2 Mechanical properties".

For example at :

Line 361 "A determining factor on the compressive strength of the four mentioned mortars was the poor quality of the recycled aggregates employed in their production." 
-3. The authors should justify how the masonry blocks of so low strength could take care of prestressing. The failure patterns of yw $-2, y w-3, y w-4$ and yw-5 show that failure occurred in concrete/masonry and not in the bond/grout possibly due to their low compressive strength. Further, at transfer, the check for stresses may be presented.

\section{Answer 3:}

The masonry mortars produced in this research work were validated according to the Cuban specifications. In order to comply with the Cuban standard NC 175:2002 [31].The type III masonry mortar (which is adequate for using at ground level and above, as rendering or bonding material) must have a minimum compressive strength value of 5.2 $\mathrm{MPa}$ at 28 days. As shown in Fig. 5, all the mortars achieved the minimum required strength value with the exception of the RM1-F-LF mortar. (see section 4.4.2. Compressive strength, Line 343).

Line 404: According to Bond tensile strength

According to Cuban regulation NC 175:2002 [31], $0.3 \mathrm{MPa}$ is the minimum bond strength value required for type III masonry mortars. That value could be reduced to $0.2 \mathrm{MPa}$ when the masonry mortars are employed as rendering or bonding for interior walls.

Line 430:" the RM2-F-LH, RM1-F-LF and RM2-F-LF mortars, produced employing recycled aggregates RA-F, which were obtained from the fine CDW fraction, did not reach the minimum strength of $0.3 \mathrm{MPa}$ needed for type III masonry mortar."

The lowest strength mortars can only be used for drying state (as rendering or bonding for interior walls), thus it is guaranteed their durability condition.

4. Authors have not qualitatively justified how the technique is economical and competent compared to other techniques.

Answer 4:

The environmental and economic study was carried out in a previous work referenced in the text:

[30] I. Muñoz Fernández, Estudio económico y ambiental del cambio de la gestión de residuos de construcción y demolición en la ciudad de La Habana, Master Thesis directed by Miren Etxeberria \& Alvar Garola, Universidad Politécnica de Cataluña (UPC), 2012, http://upcommons.upc.edu/handle/2099.1/14827.

It is a very extensive work, in consequence a reference of that work has been added to the paper. This work focused in the technical capability of the material.

5. Although the paper has been corrected in terms of English language, it still does not meet the standards of a journal like INCE. Very poor use of capital letters, spellinmistakes, poor usage of articles are not expected at this level. 
Answer 5:

A native English speaker has checked the article one more time.

6. More papers need to be referred after 2013 .

Answer 6:

This aspect has been corrected in the previous reviews. There are more than 30 papers refered which were published after 2013.

7. Units for some parameters in tables are still missing.

Answer 7:

The authors checked all tables one more time, and all the units have been added.

8. Notation for all the symbols (in alphabetical order) is required in addition to them being defined as and when they are first used in the paper.

Answer 8:

All symbols have been indicated in the section Abbreviations.

9. Methodology described is not very clear. A flow chart describing the code would help the readers. Refer the above paper for understanding how to present a flowchart.

Answer 9:

The authors think that the methodology in very clear. Several papers focused on the same issue of this work have a similar structure, without the necessity of the inclusion of any flow chart.

10. Conclusions still need revision. They are very general and qualitative in nature and appear to be mere observations. They are too long and are just repetition of the result analysis.

Answer 10:

Conclusions have been rewritten again, many modifications were included.

11. In the absence of having a clear picture of "what part of your manuscript, the comments/clarifications have been implemented" it is difficult to ensure if all the suggestions have been addressed.

Answer 11:

All the modification performed in the text have been indicated in red color (see the file "blinded manuscript_R3_with corrections"). The location of the changes are also described by the line number in the answers of reviewer's comments. 


\section{LIST OF TABLES}

Table 1. Physical properties of the natural and recycled aggregates studied.

Table 2. Chemical composition of the recycled aggregates.

Table 3. Mix proportion of masonry mortars.

Table 4. Physical properties of the hardened mortars. 
Table 1. Physical properties of the natural and recycled aggregates studied.

\begin{tabular}{|c|c|c|c|c|c|c|c|}
\hline Properties & NA & RA1-C & RA1-F & RA1-CF & RA2-C & RA2-F & $\mathrm{RA} 2-\mathrm{CF}$ \\
\hline Dry density $\left(\mathrm{kg} / \mathrm{dm}^{3}\right)$ & 2.6 & 2.13 & 1.96 & 2.08 & 2.09 & 2.02 & 2.06 \\
\hline Water absorption (\%) & 1.3 & 4.71 & 9.14 & 5.52 & 7.45 & 7.77 & 7.15 \\
\hline Bulk density $\left(\mathrm{kg} / \mathrm{dm}^{3}\right)$ & 1.48 & 1.25 & 1.05 & 1.19 & 1.16 & 1.19 & 1.22 \\
\hline Fineness modulus & 2.93 & 2.78 & 2.78 & 2.89 & 2.92 & 3.02 & 3.08 \\
\hline $\begin{array}{l}\text { Material finner than } \\
75 \mu \mathrm{m}(\%)\end{array}$ & 1 & 13 & 11 & 13 & 12 & 7 & 11 \\
\hline
\end{tabular}

Table 2.Chemical composition of the recycled aggregates.

\begin{tabular}{lllllllllll}
\hline $\begin{array}{l}\text { Elements } \\
\text { (wt \%) }\end{array}$ & $\mathrm{Fe}_{2} \mathrm{O}_{3}$ & $\mathrm{MnO}$ & $\mathrm{TiO}_{2}$ & $\mathrm{CaO}$ & $\mathrm{K}_{2} \mathrm{O}$ & $\mathrm{P}_{2} \mathrm{O}_{5}$ & $\mathrm{SiO}_{2}$ & $\mathrm{Al}_{2} \mathrm{O}_{3}$ & $\mathrm{MgO}$ & $\mathrm{Na}_{2} \mathrm{O}$ \\
\hline RA1-C & 4.93 & 0.08 & 0.38 & 26.09 & 0.83 & 0.08 & 47.43 & 13.29 & 3.82 & 2.21 \\
RA1-F & 4.94 & 0.07 & 0.13 & 24.08 & 0.22 & 0.23 & 47.83 & 3.26 & 14.65 & 0.30 \\
RA1-CF & 5.64 & 0.09 & 0.28 & 27.16 & 0.55 & 0.08 & 41.47 & 8.92 & 11.88 & 1.41 \\
RA2-C & 4.06 & 0.07 & 0.23 & 47.01 & 0.68 & 0.15 & 31.31 & 7.86 & 5.81 & 1.10 \\
RA2-F & 3.90 & 0.07 & 0.15 & 60.14 & 0.27 & 0.25 & 18.25 & 3.65 & 9.22 & 0.24 \\
RA2-CF & 3.92 & 0.07 & 0.22 & 47.96 & 0.50 & 0.13 & 27.00 & 5.74 & 7.86 & 0.79 \\
\hline
\end{tabular}

Table 3. Mix proportion of masonry mortars.

\begin{tabular}{llllllll}
\hline Nomenclature & $\begin{array}{l}\text { Volumetric } \\
\text { proportion }\end{array}$ & Aggregate & Filler & $\begin{array}{l}\text { Total w/c } \\
\text { ratio }\end{array}$ & $\begin{array}{l}\text { Effective } \\
\text { w/c ratio }\end{array}$ & $\begin{array}{l}\text { Consistency } \\
(\mathrm{mm})\end{array}$ & $\begin{array}{l}\text { Water } \\
\text { retentivity (\%) }\end{array}$ \\
\hline CM-LH & $1: 4: 2$ & NA & LH & 1.31 & 1.28 & 195 & 91.3 \\
RM1-C-LH & $1: 5: 1$ & RA1-C & LH & 1.9 & 1.77 & 189 & 92.2 \\
RM1-F-LH & $1: 5: 1$ & RA1-F & LH & 1.61 & 1.41 & 189 & 90.9 \\
RM1-CF-LH & $1: 5: 1$ & RA1-CF & LH & 1.65 & 1.49 & 187 & 90.1 \\
RM2-C-LH & $1: 5: 1$ & RA2-C & LH & 1.98 & 1.79 & 190 & 90.8 \\
RM2-F-LH & $1: 5: 1$ & RA2-F & LH & 1.75 & 1.55 & 189 & 92.9 \\
RM2-CF-LH & $1: 5: 1$ & RA2-CF & LH & 1.82 & 1.63 & 187 & 92.4 \\
CM-LF & $1: 4: 2$ & NA & LF & 1.41 & 1.38 & 191 & 89.3 \\
RM1-C-LF & $1: 5: 1$ & RA1-C & LF & 1.9 & 1.78 & 189 & 90.6 \\
\hline
\end{tabular}




\begin{tabular}{llllllll}
\hline RM1-F-LF & $1: 5: 1$ & RA1-F & LF & 1.68 & 1.49 & 194 & 90.3 \\
RM1-CF-LF & $1: 5: 1$ & RA1-CF & LF & 1.66 & 1.52 & 185 & 90 \\
RM2-C-LF & $1: 5: 1$ & RA2-C & LF & 1.98 & 1.81 & 191 & 90.4 \\
RM2-F-LF & $1: 5: 1$ & RA2-F & LF & 1.8 & 1.6 & 190 & 90.8 \\
RM2-CF-LF & $1: 5: 1$ & RA2-CF & LF & 1.86 & 1.68 & 186 & 90.7
\end{tabular}

${ }^{*}$ Volumetric and gravimetric proportions (cement: aggregate: filler)

Table 4. Physical properties of the hardened mortars.

\begin{tabular}{llll}
\hline Mortars & Density $\left(\mathrm{kg} / \mathrm{m}^{3}\right)$ & Water absorption (\%) & Porosity (\%) \\
\hline CM-LH & 2086 & 13.8 & 25.3 \\
RM1-C-LH & 1864 & 23.3 & 35.2 \\
RM1-F-LH & 1779 & 28.9 & 39.8 \\
RM1-CF-LH & 1872 & 24.2 & 36.5 \\
RM2-C-LH & 1840 & 25.4 & 37.3 \\
RM2-F-LH & 1824 & 22.3 & 33.6 \\
RM2-CF-LH & 1861 & 19.3 & 30.2 \\
CM-LF & 2125 & 13.3 & 24.9 \\
RM1-C-LF & 1913 & 20.3 & 32.3 \\
RM1-F-LF & 1809 & 26.7 & 38.1 \\
RM1-CF-LF & 1896 & 22.1 & 34.3 \\
RM2-C-LF & 1888 & 22.7 & 34.9 \\
RM2-F-LF & 1880 & 20.7 & 32.2 \\
RM2-CF-LF & 1901 & 20.1 & 31.5 \\
\hline
\end{tabular}




\section{LIST OF FIGURES}

Fig. 1. Source of CDW 1 and 2 (figures $A$ and $B$, respectively), and recycled mortars placed over concrete blocks (figure C).

Fig. 2. Particle size distribution of the fillers used.

Fig. 3. Particle size distribution of the aggregates studied and rage determined by the Cuban standard (NC 657:2008 [37], equivalent to ASTM C144-99 [38]).

Fig. 4. Electrical Resistivity test.

Fig. 5. Compressive strength (the standard deviation is presented at the top of each column) of the mortars studied. The red line marks the minimum value $(5.2 \mathrm{MPa})$ required by Cuban standard.

Fig. 6. Flexural strength (the standard deviation is presented at the top of each column) of the mortars studied.

Fig. 7. Bond tensile strength (the standard deviation is presented at the top of each column) of the mortars studied. The red lines mark the values $(0.2 \mathrm{MPa}$ and $0.3 \mathrm{MPa})$ required by Cuban standard to define the mortar application.

Fig. 8. Capillary absorption as a function of time of hydrated lime mortars.

Fig. 9. Capillary absorption as a function of time of lime filler mortars.

Fig. 10. Drying shrinkage of mortars produced with lime hydrate.

Fig. 11. Drying shrinkage of mortars produced with lime filler.

Fig. 12. Electrical resistivity of mortars at 28 days. 


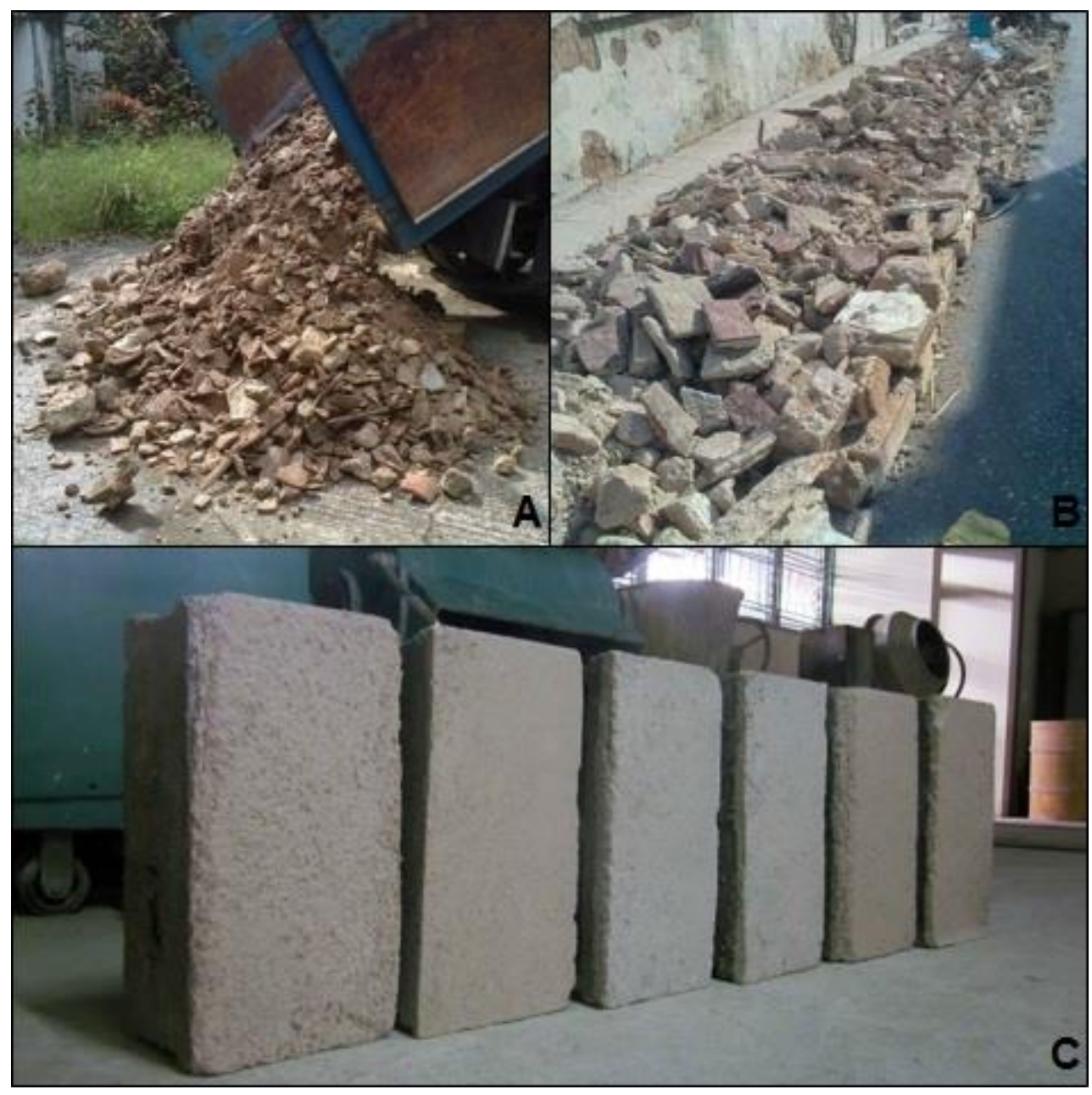

Fig. 1. Source of CDW 1 and 2 (figures A and B, respectively), and recycled mortars placed over concrete blocks (figure $\mathrm{C}$ ). 


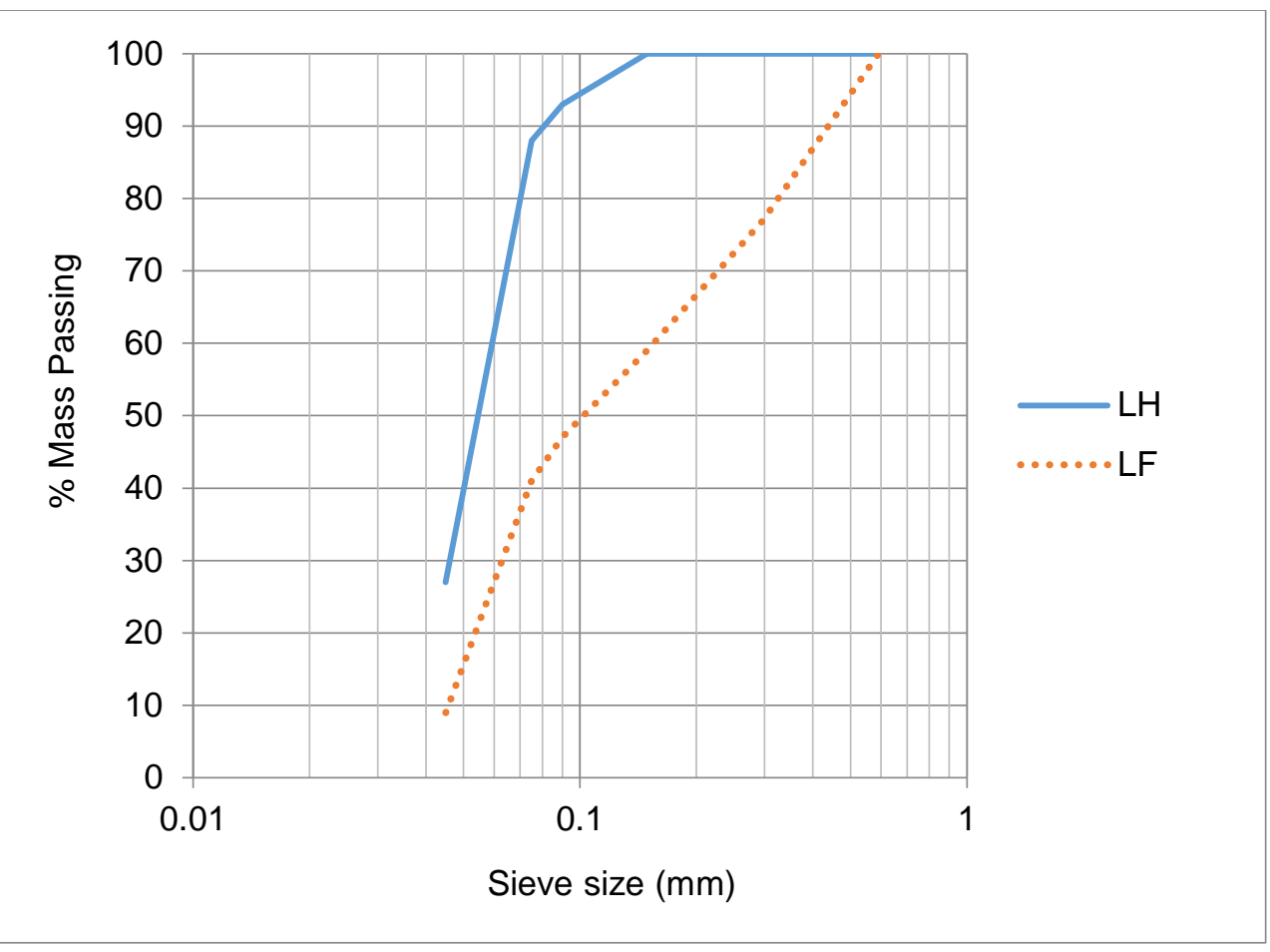

Fig. 2. Particle size distribution of the fillers used.

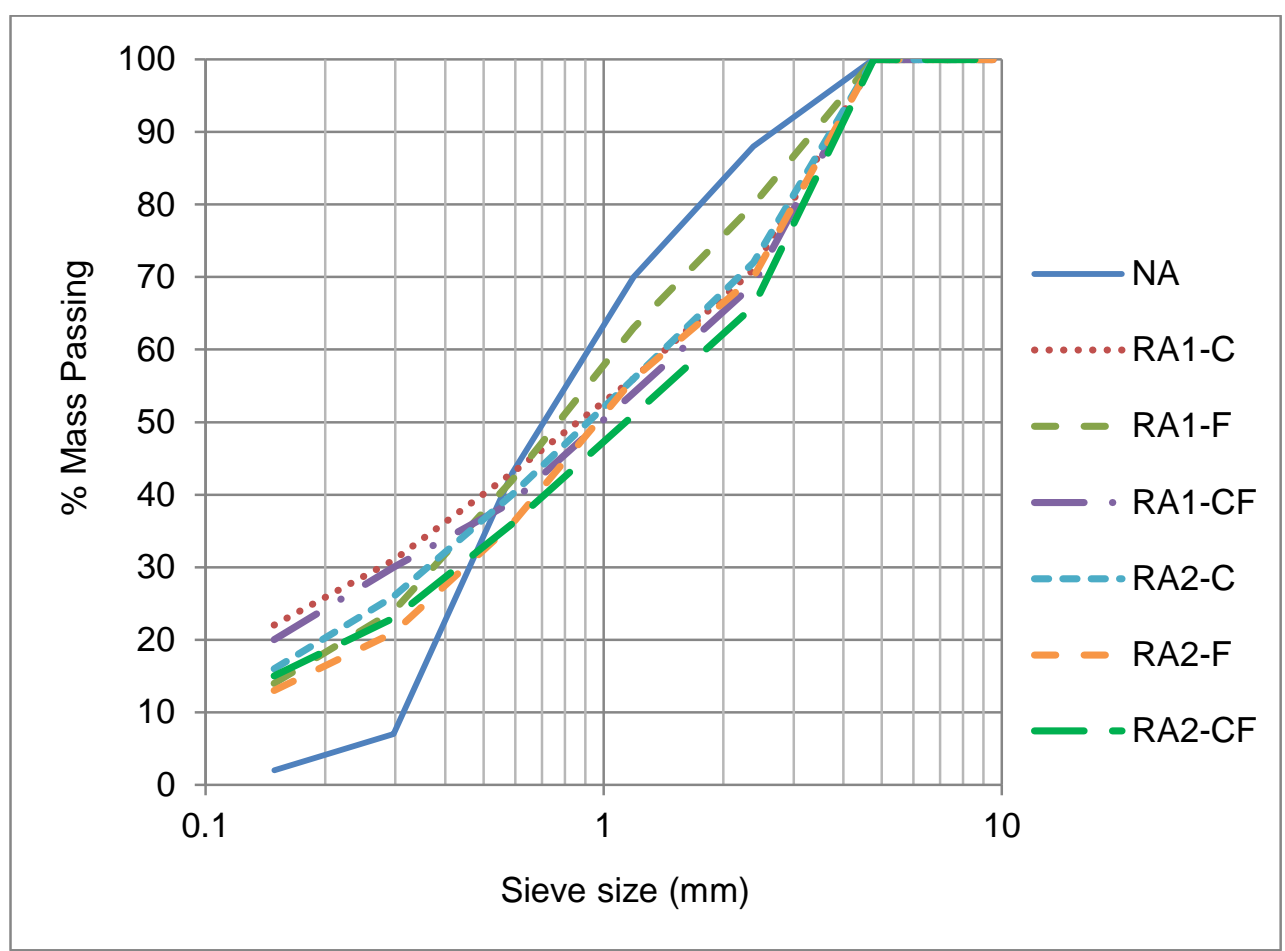

Fig. 3. Particle size distribution of the aggregates studied. 


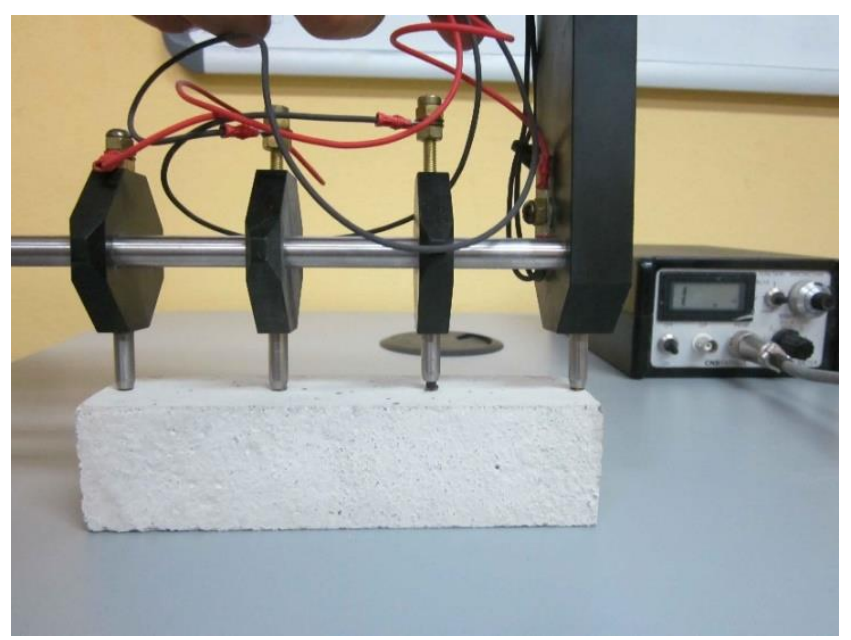

Fig. 4. Electrical Resistivity test.

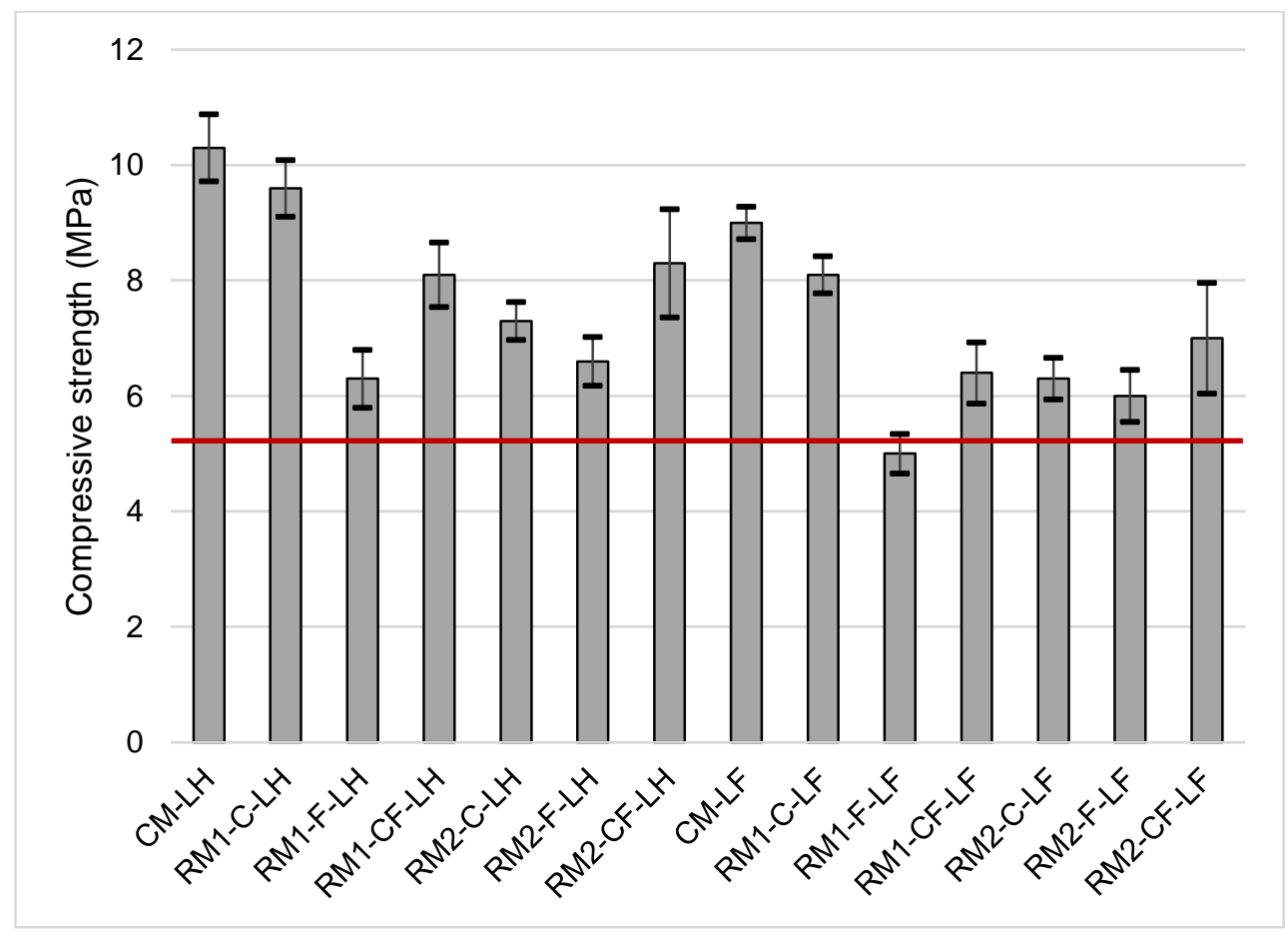

Fig. 5. Compressive strength (the standard deviation is presented at the top of each column) of the mortars studied. The horizontal line marks the minimum value (5.2 $\mathrm{MPa})$ required by Cuban standard. 


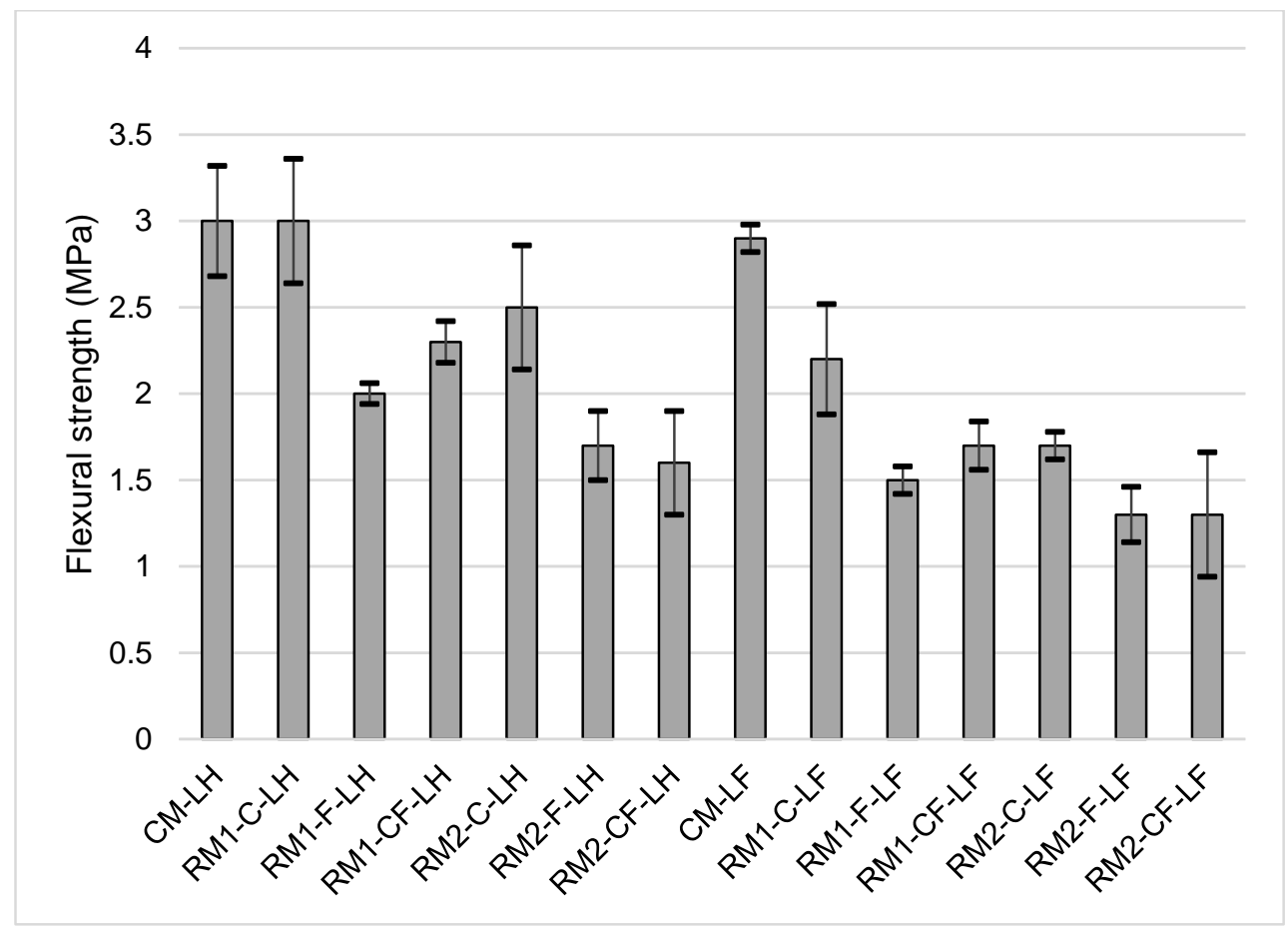

Fig. 6. Flexural strength (the standard deviation is presented at the top of each column) of the mortars studied.

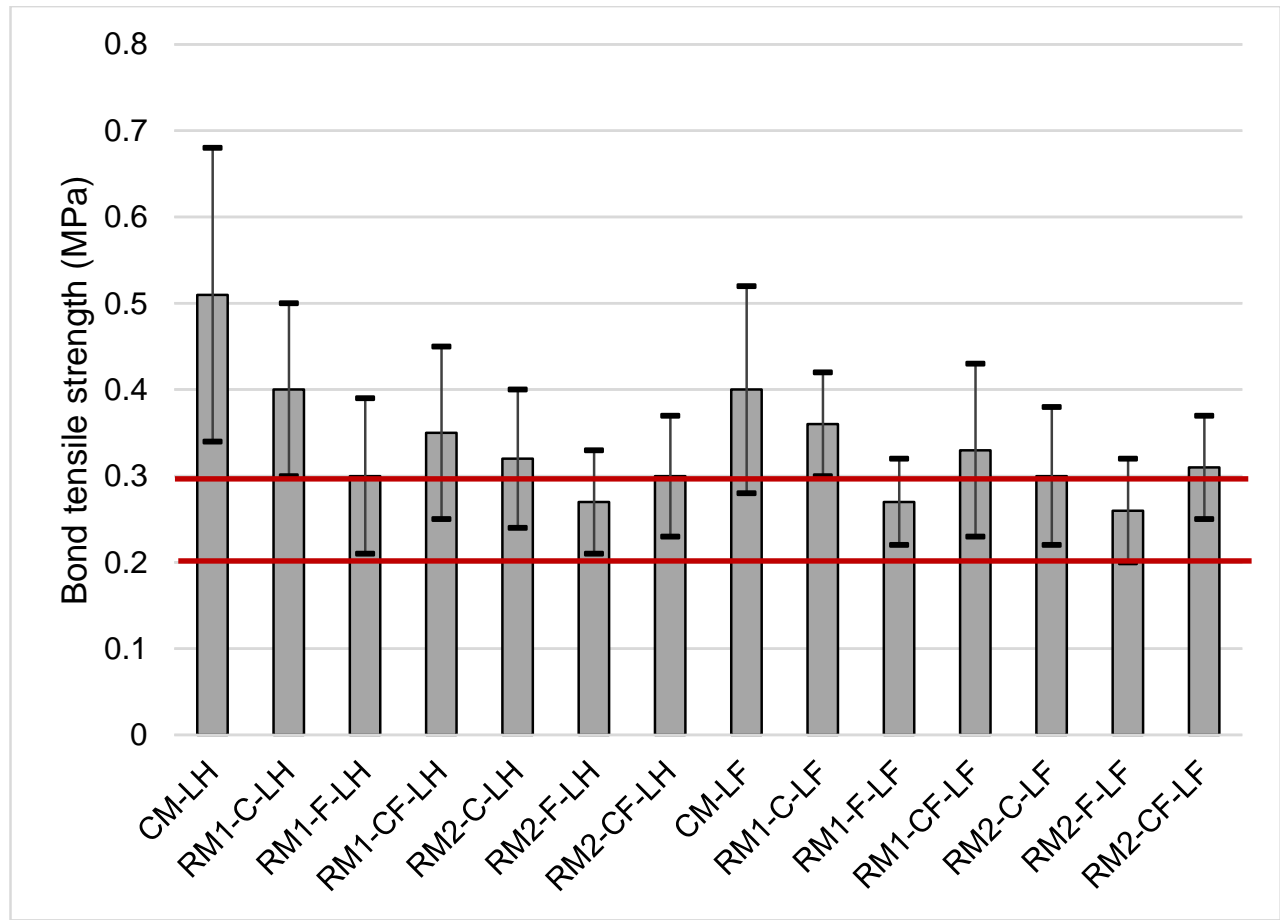

Fig. 7. Bond tensile strength (the standard deviation is presented at the top of each column) of the mortars studied. The horizaontal lines mark the values $(0.2 \mathrm{MPa}$ and $0.3 \mathrm{MPa})$ required by Cuban standard to define the mortar application. 


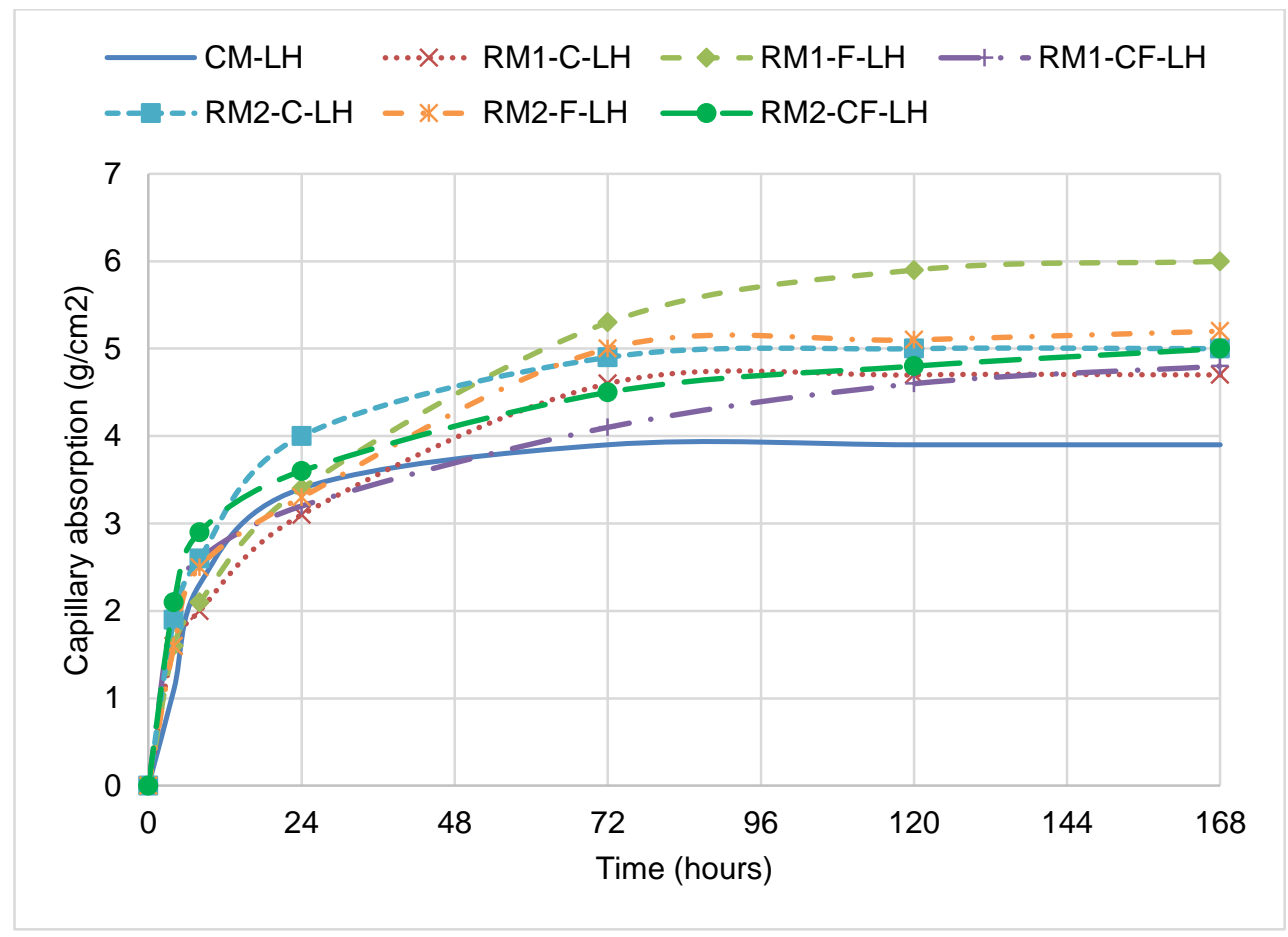

Fig. 8. Capillary absorption as a function of time of hydrated lime mortars at 28 days of curing.

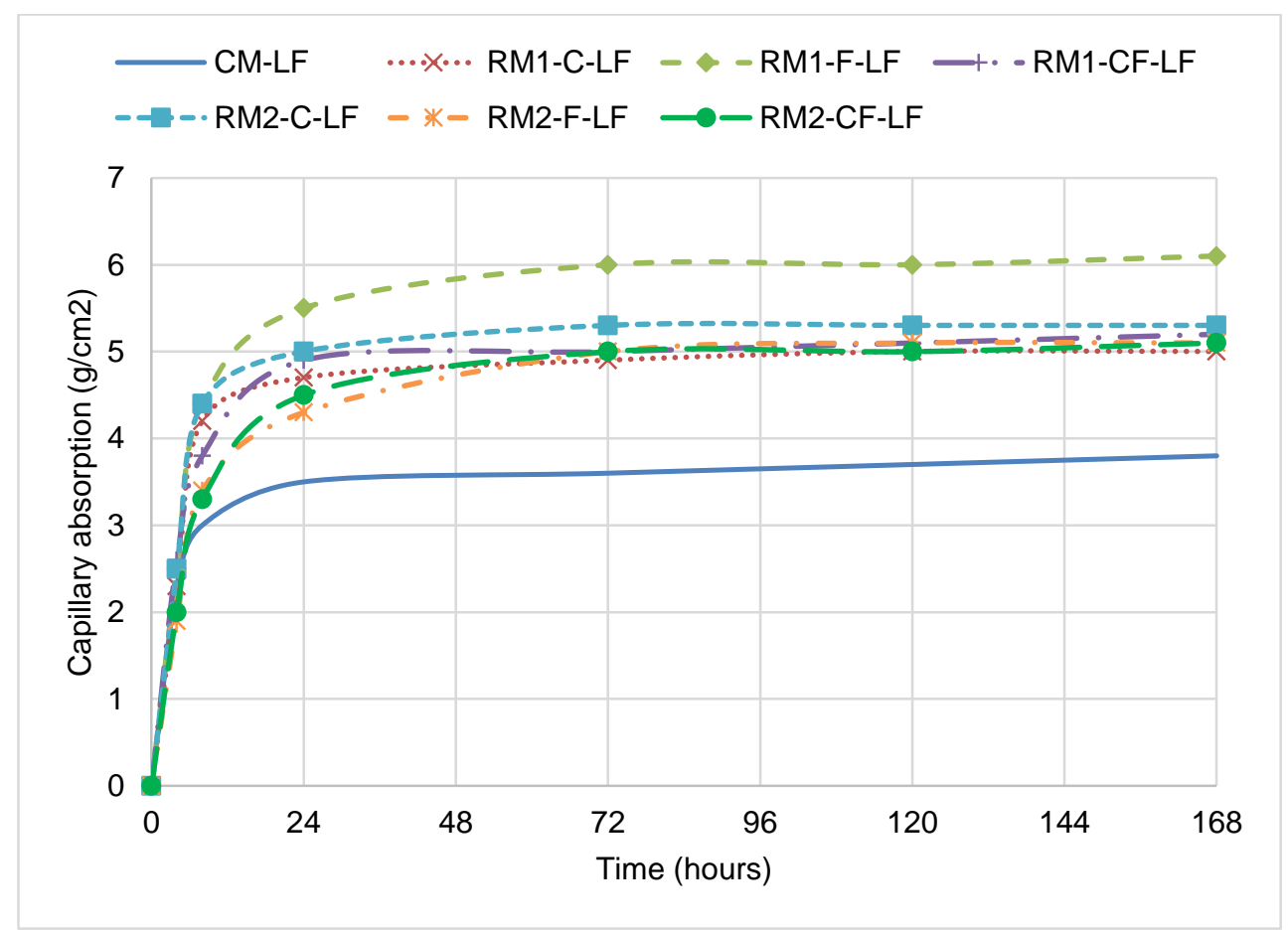

Fig. 9. Capillary absorption as a function of time of lime filler mortars at 28 days of curing. 


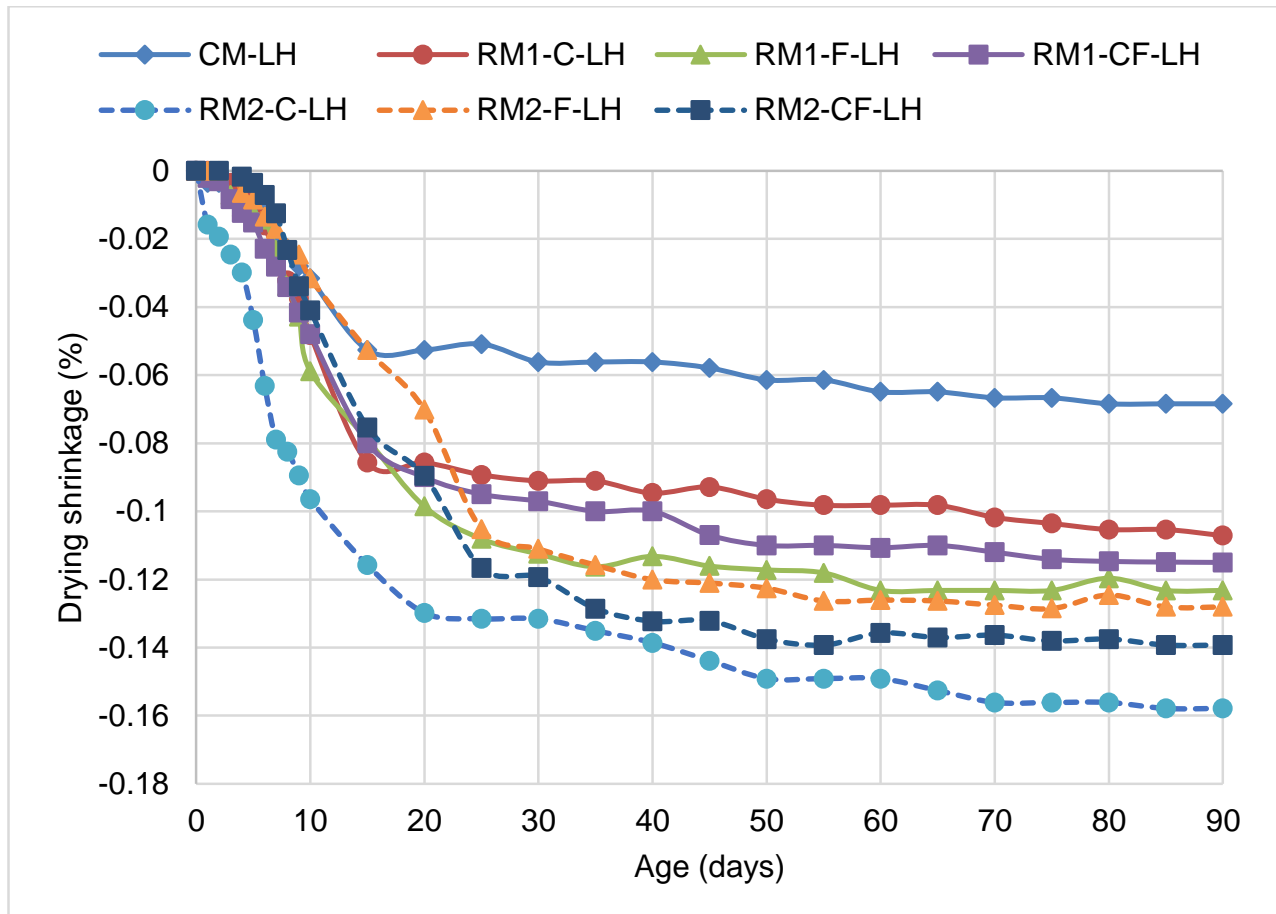

Fig. 10. Drying shrinkage of mortars produced with lime hydrate.

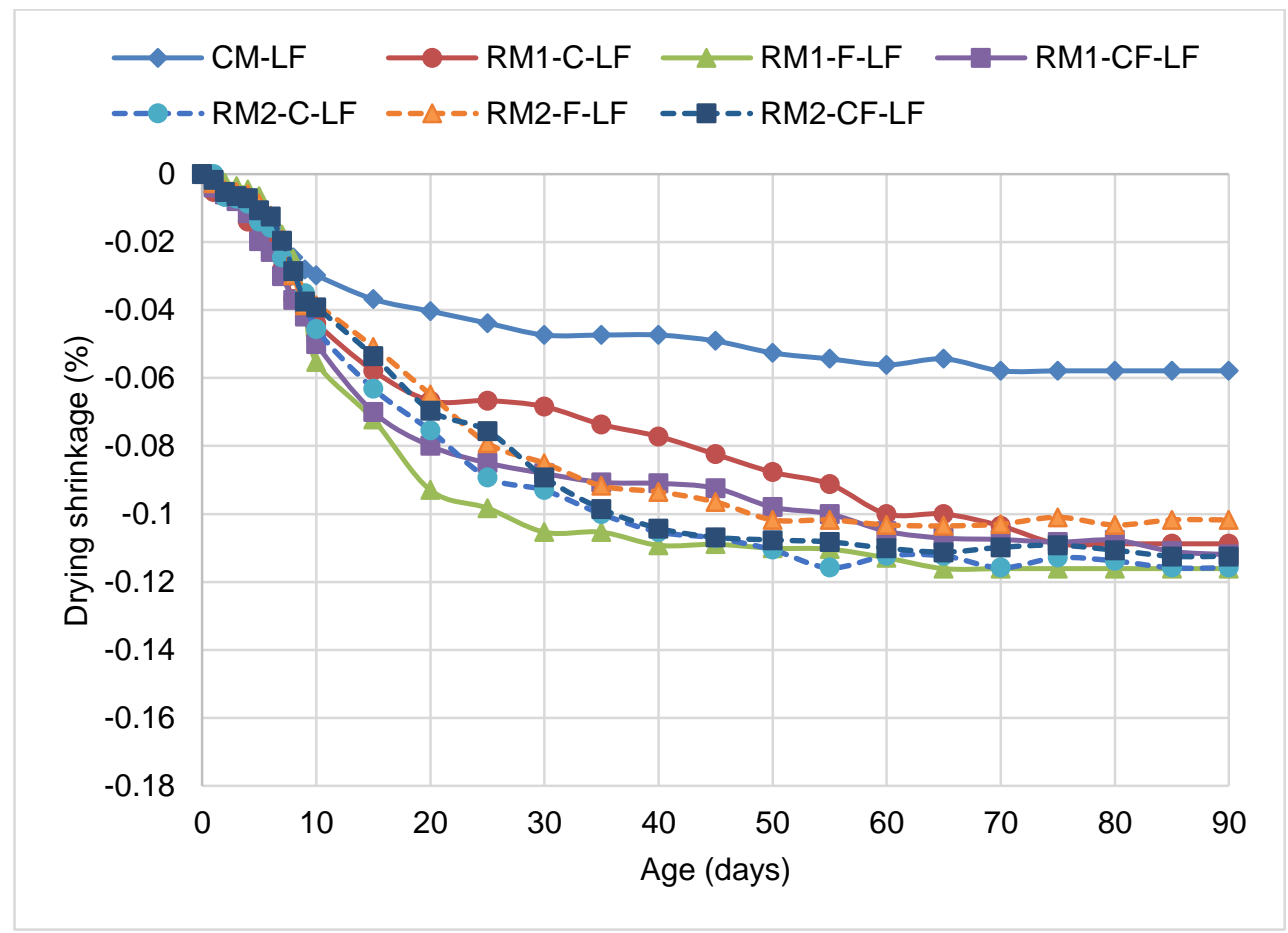

Fig. 11. Drying shrinkage of mortars produced with lime filler. 


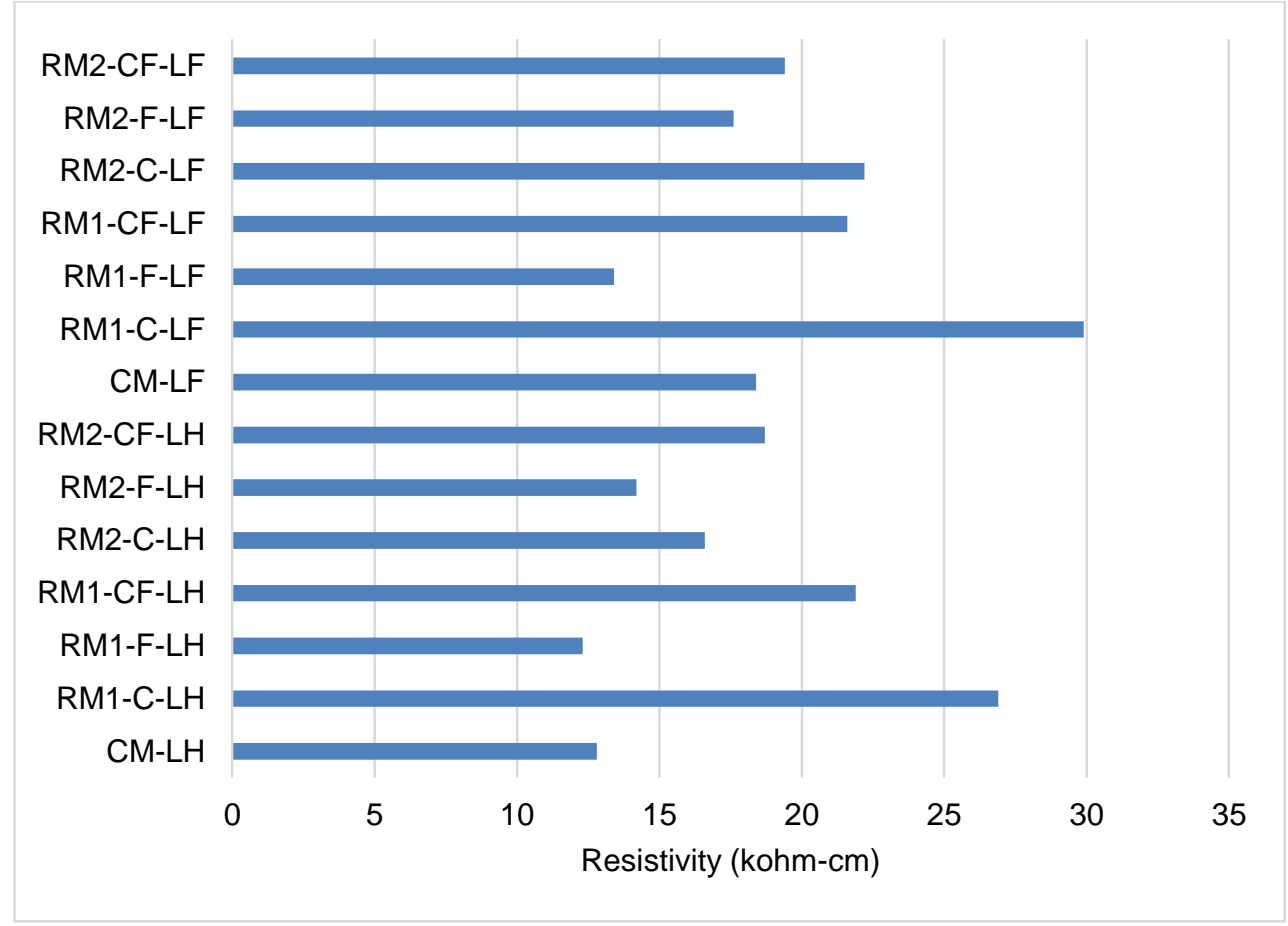

Fig.12. Electrical resistivity of mortars at 28 days. 


\section{Influence of demolition waste fine particles on the properties of recycled aggregate} 2 masonry mortar

3

4 Abstract

5 This paper analyses the influence of the fine fraction of two types of construction and 6 demolition waste (CDW1 and CDW2) on the properties of recycled aggregates (RA) and 7 masonry mortars. The CDW1's main component was ceramic while the CDW2 were 8 concrete. Three different kinds of fine RA were produced from each source of CDW; the

9 first type was produced by only using the fraction finer than $4.76 \mathrm{~mm}$, the second one by 10 employing only the coarser fraction than $4.76 \mathrm{~mm}$, and the third type was a mix of both 11 fractions of CDW. The masonry mortars were produced employing the 100\% substitution 12 of natural aggregates. The results show that all the recycled mortars achieved a higher 13 water retentivity capacity than that of the conventional mortars. However, the sole use of 14 the fine fraction of the CDW was found to have a deleterious effect over the hardened 15 mortar properties, thus making it only adequate for the rendering or bonding of interior 16 walls at or above ground level. In contrast a combination of both the fine fraction and 17 coarse fraction of the CDW in the production of the RA achieved all the minimum 18 requirements for rendering and bonding masonry mortar.

\section{Highlights}

- Two sources of CDW, one with ceramic and other with concrete as main components, 22 were employed.

23 - Three different RA were obtained from two different sources of CDW.

24 - Masonry mortars employing $100 \%$ of recycled aggregate were validated.

- Ceramic high content recycled aggregates mortars achieved the most adequate 26 properties.

- The employment of the coarse fraction of the CDW guarantee high quality aggregates for masonry mortar.

30 Keywords: Masonry mortar; fine recycled aggregate; recycled aggregate mortar; construction and demolition waste; fresh mortar properties; mechanical properties. 


\section{Abbreviations}

34 CDW - Construction and demolition waste

35 FRA - Fine recycled aggregate

36 LH - Lime hydrate

$37 \quad$ LF - Limestone filler

$38 \quad$ RA - Recycled aggregate

$39 \mathrm{w} / \mathrm{c}$ - water/cement

40

\section{Introduction}

42 The use of recycled aggregates obtained from the recycling of construction and 43 demolition waste (CDW) is a sustainable alternative to the employment of natural 44 aggregates within the construction industry [1]. This alternative not only allows for the protection of natural resources but is also instrumental in the reduction of areas used for landfill [2]. There have been many studies with respect to the mentioned environmental benefits [3-6], although most of the studies have been focused on the use of recycled aggregates for concrete production [7-12]. Several researchers have also studied the applicability of fine recycled aggregates (FRA) for mortar production due to the high amount of FRA produced as a result of the CDW treatment process [13-20].

51 Most of the mortar mixes manufactured with higher percentages of recycled aggregate presented lower mechanical properties than those of conventional mortar $53[13,14,16,17,19,20]$. However, certain authors have established that there were minor

54 influences on the properties of mortar mixes produced with a replacement ratio of up to $20 \%$ [21,22], $25 \%$ [19] or $40 \%$ [15] of recycled aggregate in substitution of natural aggregate. According to several researches [23-26] the improvements on the mortars' properties were also achieved when fine ceramic and concrete aggregates were employed in the mortar production or the quality of the recycled aggregates were improved after their treatment [27]. 
The CDW, which can be recycled, is available in numerous countries as a result of human

61 intervention or natural disasters [28]. According to the information obtained from the

62 Cuban National Statistics and Information Office, approximately $1000 \mathrm{~m}^{3}$ of CDW is generated per day in Havana. The largest volume of CDW being located in landfill sites, which effectively makes it unusable for recycling due to the resulting mixing of materials and consequent contamination [29]. In Cuba, uncontaminated waste is not recycled due to deficiencies in adequate technological infrastructures as well as a lack of an adequate policy with respect to the management of this type of waste [30].

The natural aggregate quarries located near the city are almost depleted as a result of their over exploitation. Consequently, natural aggregates have to be obtained from new quarries which are a long distance away from the city, with the following consequences of higher economic costs as well as having a negative environmental impact on the local landscape [30].

Masonry mortars are widely employed in the construction of buildings in Havana, in general social housing, which is the cause of the highest aggregate consumption. The mechanical properties required for rendering or bonding mortars, according to the Cuban standard [31], are relatively low (less than $10 \mathrm{MPa}$ of compression strength), allowing the use of a low cement content in the mortar manufacture.

As a direct consequence of the lack of natural fine aggregates the locals in Havana have used for the maintenance and renovation of their buildings recycled material with fractions finer than $5 \mathrm{~mm}$ (without crushing) obtained directly from demolished or collapsed building waste. Its use is carried out without undergoing a process of selection and treatment, as a consequence of which this fine aggregate material is often of poor quality due to its contamination by detrimental material. Fig. 1 shows several images of both sources of CDW and the mortar mixes produced.

In this research work the two different sources of CDW, which are most typical in Havana, were treated for the production of fine recycled aggregates and their applicability for masonry mortar was production analyzed. The recycled aggregates were used in total replacement of natural aggregates. Material taken from both of the CDW sources was submitted to three different crushing processes, which led on to three types of recycled aggregates being produced from each type of CDW under study. A total of six types of recycled aggregates were employed in this work. The influence of these processes on the 
92 properties of the recycled aggregates, and their applicability, in total replacement of 93 natural aggregates, in mortar production were the main objectives of this research work.

94 Two types of fillers were also used in the manufacturing of the mortar; hydrated lime 95 (recommended by Cuban standard) and limestone filler (widely employed in the city due 96 to its high availability). The physical, mechanical and durability properties of the recycled 97 aggregate mortar mixes were analyzed and their results were compared with those of the 98 results obtained from the analysis of a standard conventional mortar, as well as with the 99 minimum requirements as defined by Cuban specification NC 175:2002 [31] (equivalent 100 to ASTM C270-12 [32]) for type III masonry mortar production.

101

102

\section{Materials}

103

\subsection{Cement}

104 An ordinary Portland cement P-350, which according to Cuban standard NC 95:2001 [33], 105 equivalent to ASTM Type I, was employed for all mortar production. It had a density of $1063.12 \mathrm{~g} / \mathrm{cm}^{3}$, specific surface of $3089 \mathrm{~g} / \mathrm{cm}^{2}$ and a compressive strength of $35 \mathrm{MPa}$ at 28 107 days.

108

$109 \quad 2.2$ Fillers

110 Two different types of fillers were employed for mortar production: lime hydrate (LH) 111 and limestone filler (LF). According to NC 175:2002 [31] the LH which had a dry density 112 and bulk density of $2.1 \mathrm{~kg} / \mathrm{dm}^{3}$ and $0.52 \mathrm{~kg} / \mathrm{dm}^{3}$ respectively, was considered to be an 113 adequate filler for masonry mortar production. The LF, which had a dry density of 2.58 $114 \mathrm{~kg} / \mathrm{dm}^{3}$ and bulk density of $1.14 \mathrm{~kg} / \mathrm{dm}^{3}$, was produced via the grinding of limestone 115 aggregates. LF material is predominantly used within the city of Havana due to the 116 difficulty of obtaining lime hydrate. Fig. 2 illustrates the particle size distribution of both 117 filler materials. 
120 2.3.1 Production and composition of the recycled fine aggregates

121 The recycled aggregates used in the present work were obtained from two different CDW sources (CDW1 and CDW2). Both types of CDW were representative of the two most common types of dwellings built in Havana, which date back to the middle of the past century. The CDW1 waste material was obtained from the demolition of buildings with ceramic tiled roofs and compacted earth and limestone walls. In contrast, the CDW2 waste was obtained from the demolition of buildings with roofs formed of steel beams and concrete slabs with the walls consisting of ceramic brick. The general composition of the CDW wastes was that of roof and wall elements, however, other materials were also found to be present such as mortar, tiles, etc, which proved to be less than $10 \%$ of the total weight of the whole. An important percentage of the CDW generated in the capital of Havana is produced by the demolition of this type of dwelling [30].

132 The representative sampling was carried out after the crushing of between 3 and 4.5 tons

133 of each of the two types of CDW mentioned and in accordance with BS-EN 932-1:1997

134 regulations [34]. Both types of CDW were individually submitted to three different types 135 of crushing processes for the production of three different kinds of recycled aggregates ($136 \mathrm{C},-\mathrm{F}$ and $-\mathrm{CF})$.

137 The process adopted for the obtaining of the first type of fine recycled aggregates (RA1/2-

138 C) was carried out by firstly discarding all material finer than the $4.76 \mathrm{~mm}$ sieve from the 139 total volume of the CDW prior to it passing through the crushing stage. Secondly, the 140 total volume of the material greater than $4.76 \mathrm{~mm}$ was crushed via the employment of a 141 jaw crusher for the production of RA1/2-C fine recycled aggregates [14,29]. For the 142 production of the second type of fine recycled aggregates, RA1/2-F, the CDW material 143 which proved to be finer than the $4.76 \mathrm{~mm}$ sieve was used without undergoing any 144 crushing process. The third and last type of fine recycled aggregates, RA1/2-CF, were 145 obtained via the crushing of the total volume of the CDW to that of a finer material than $1464.76 \mathrm{~mm}$. In all three types of processes the material finer than $4.76 \mathrm{~mm}$ was separated 147 after every stage of crushing and the remaining fractions found to be coarser than that 148 size were submitted to a new crushing process. The crushing process was completed when 149 all the material accomplishment the desired particle size. 
152 Raw limestone aggregate obtained from the Arimao quarry which is the highest quality 153 commercialized aggregate in the city [14] was used for the production of the control 154 mortar.

155 Fig. 3 shows the particle size distribution of all the types of aggregates used in the present 156 study. They were determined following NC 178:2002 [35] specification (equivalent to 157 ASTM C136/C136M-14 [36]). The range established by Cuban standard NC 657:2008 158 [37] (equivalent to ASTM C 144 [38]) for aggregates for masonry mortar is alse

159 illustrated in the graph. All the recycled aggregates were found to have a similar grading 160 distribution, however when compared to those of the recycled aggregates, the natural aggregates were found to present a lower amount of finer aggregates than $0.297 \mathrm{~mm}$, see Fig. 3. Tests proved that the recycled aggregates not only presented a higher percentage 163 of material finer than $75 \mu \mathrm{m}$, but that they also had lower amounts of passing material 164 through the higher grade sieve than those of the natural aggregates.

165 Table 1 shows the physical properties of the natural and recycled aggregates. The density 166 and water absorption capacity were evaluated according to Cuban standard NC 177:2002 167 [37] (equivalent to ASTM C29/C29M-17 [38] specification). The bulk density and the 168 percentage of the material passing through No. $200(<75 \mu \mathrm{m})$ sieve were determined 169 following NC 181:2002 [39] (equivalent to ASTM C29/C29M-17 [38]) and NC 182:2002 170 [40] (equivalent to ASTM C117-13 [41]) specifications, respectively.

171 The water absorption capacity of all the recycled aggregates proved to be greater than that 172 of the natural aggregate (Table 1), a fact which has also been reported by other researchers $173[13,17-19,22,26,42-44]$. With respect to recycled aggregates, those obtained from 174 crushing the fine and coarse fraction of CDW1 achieved the highest and lowest absorption 175 capacity, respectively. The water absorption capacity of the three recycled aggregates obtained from CDW2 was similar to or higher than that of RA1-C.

177 Table 2 shows the chemical composition of the recycled aggregates, which was 178 determined via Panalytical, Axios PW 4400/40 XRF spectrometers. The calcium and 179 silica content being the main differences between the CDW1 and CDW2 sources. The 180 recycled aggregates produced from the CDW1 source proved to contain approximately $18150 \%$ of silica, as a direct consequence of its high percentage of ceramic material content.

182 The recycled aggregates produced from the CDW2 had a higher composition of calcium, 
as they originated from concrete elements. The magnesium and aluminum content proved to be the main difference between the composition of the coarse (-C) and fine (-F) fraction. The RA1-F aggregates proved to have a high content of magnesium due to the presence of limestone rocks, as the walls of the dwellings, which formed part of the material sourced for CDW1, had a certain amount of dolomite content in them. In contrast, the RA1-C aggregate proved to have a greater aluminum content, which was a direct result of the influence of the coarse fraction of the ceramic roof material. With respect to the RA2-F aggregate produced from the CDW2 waste, it was determined that the high magnesium value (limestone-dolomite aggregates were used for concrete production) was a direct result of the high content of material obtained from the concrete roofing. In contrast the RA2-C aggregate, which was obtained from ceramic wall waste, proved to have higher amounts of aluminum content.

\section{Mortar Manufacture and Experimental Procedure}

\section{$197 \quad 3.1$ Mortar mixture proportions}

198 Type III Control mortar (bonding and rendering mortar for use at ground level and above) 199 employing natural aggregate, with the volumetric mix proportion of 1:4:2 (cement: aggregate: filler) was produced following NC 175:2002 [31] specifications. This standard recommends the use of lime hydrate as filler. Unfortunately, this is difficult to obtain within Havana and as a consequence the use of limestone filler is also permitted in mortar manufacture. As a direct result of the lack of fine particles within the natural aggregates it is necessary to include filler in the mortar mixture. The mentioned added filler has the effect of reducing the volume of voids within the particle matrix, thus achieving a better performance of the mortars in the fresh and hardened state [45].

207 The 1:5:1 (cement: aggregate: filler) volumetric mix proportion was used for the recycled aggregate mortars production. Prior studies [14] verified that this dosage was the equivalent to the volumetric dosage (1:4:2) established by Cuban regulations for natural aggregates mortars. The higher amount of fine material contained in the recycled aggregate justified the reduction in the use of the filler volume.

212 The manufacturing process was carried out following NC 173:2002 [46] (equivalent to

213 ASTM C348-14 [47] and ASTM C349-14 [48]) specifications. The total water content 214 added to each mortar was determined experimentally in order to obtain a consistency 
215 index of $190 \pm 5 \mathrm{~mm}$ in all mortar mixes, and in accordance with Cuban standard NC

216 170:2002 [49] (equivalent to ASTM C1437-15 [50]). The quantity of free water in the

217 paste of each of the mortar mixes defined the effective water cement ratio (see table 3 ).

218 The natural aggregates were used in dry condition while the recycled aggregates were

219 used in wet condition. The effective water absorption capacity of the fine aggregates was

220 determined via soaking them for 30 min (defined by DIN 4226-100 [51]). The method

221 used in the testing was that stipulated by the Cuban regulation NC 186: 2002 [52]

222 (equivalent to ASTM C 128-97 [53]) for the determination of the $24 \mathrm{~h}$ absorption capacity

223 of natural aggregates. The effective absorption capacity of the recycled and natural

224 aggregates was $80 \%$ and 50\% respectively of their total absorption capacity.

225 Twelve different recycled aggregate mortar mixes were produced, as a result of the 226 combination of the six recycled aggregates (RA1-C, RA1-F, RA1-CF, RA2-C, RA2-F 227 and RA2-CF) with the two fillers (LH, LF). Two control mortars were also manufactured 228 employing natural sand and two types of fillers. Table 3 shows the mix proportions of the 229 mortars.

230 The mortar specimens were de-molded at 24 hours and then, in compliance with 231 regulation NC 173:2002 [46] (equivalent to ASTM C348-14 [47] and ASTM C349-14 232 [48]), cured in a humidity room until the testing stage.

\subsection{Experimental procedure}

\subsubsection{Fresh state test}

236 The consistency and water retentivity properties were measured. The consistency of 237 mortar was fixed as $190 \pm 5 \mathrm{~mm}$ for all the mortar mixes in accordance with NC 170:2002 238 [49] (equivalent to ASTM C1437-15 [50]) specifications. The mortar mixes which did 239 not achieve that requirement were rejected.

240 The water retentivity capacity was determined in all of the mortar mixes in accordance 241 with NC 169:2002 [54] (equivalent to ASTM C1506-16b [55]) specifications. The fresh 242 mortar was poured into a $100 \mathrm{~mm}$ diameter cylindrical mould, with a depth of $25 \mathrm{~mm}$, 243 before being subjected to a suction test employing a specific absorption filter. The water 244 retentivity capacity was determined by the amount of water absorbed by the paper filter, 245 being $90 \%$ the minimum value required by Cuban Specification. 
247 3.2.2. Hardened state tests

248 Physical (density, absorption and accessible pores) and mechanical (compressive and 249 flexural strength) properties were determined after 28 days of curing according to ASTM 250 C270-12a [32] and NC 173:2002 [46] (equivalent to ASTM C348-14 [47] and ASTM 251 C349-14 [48]) specifications, respectively, employing the Automax compression 252 equipment with $50 \mathrm{kN}$ capacity.

253 The mortar bond tensile strength was also determined, following the NC 172:2002 [56]

254 specifications. The test, which was carried out over a concrete block surface via the use 255 of a Dyna Haftprufer Pull-off tester Z16 (as described in the previous work [14]), at 28 256 days of curing and in similar conditions to those of the other test specimens.

257 The capillary water absorption capacity of each mortar was also determined after 28 days 258 of curing according to NC 171:2002 [57] (equivalent to ASTM C1403-15 [58]) 259 specifications. All the surfaces of the specimens were sealed with an epoxy resin except 260 for the top and bottom ends of $40 \times 40 \mathrm{~mm}$ which were left untreated in order to ensure 261 the one directional transport of the water as described by the regulation.

262 The drying shrinkage was determined according to ASTM C490/C490M-11 [59] 263 specifications. The $25 \times 25 \times 285 \mathrm{~mm}$ mortar specimens, which had been fitted with a 264 stainless steel stud at both ends, were de-molded after 24 hours of casting and kept in an 265 environmental temperature of $28^{\circ} \mathrm{C}$ with a humidity of $80 \%$. The initial length readings 266 were immediately recorded via the use of a length comparator model 62-L0035/A. The 267 length variation was measured over a period of 90 days.

268 The electrical resistivity was determined via the use of a model Vasrmmk11 tester (see 269 Fig. 4). The measurements were taken with the specimens in a saturated condition which 270 was achieved by totally submerging the specimens in water for 24 hours after undergoing 27128 days of curing. 


\section{Results and Discussion}

\section{$274 \quad$ 4.1 Fresh state properties}

275 4.1.1 Consistency

276 It was necessary to vary the water content employed for the production of the mortars in order to obtain the required consistency of $190 \pm 5 \mathrm{~mm}$. The variation of water content was carried out without using admixtures. Table 3 shows the consistency values obtained by all the mortar mixes produced. The recycled aggregate mortars needed more water than the control mortars in order to achieve the required workability values $(190 \pm 5 \mathrm{~mm})$ established by Cuban regulation NC 170:2002 [49] (equivalent to ASTM C1437-15 [50]).

The higher absorption capacity of recycled aggregates with respect to natural aggregates has a negative effect on the consistency of the mortar produced, as the recycled aggregates absorb part of the mixing water $[17,18,60,61]$. Additionally, mixtures produced with angular and rough-textured particles, such as those found in recycled aggregates, tend to interlock and reduce inter-particle movement [62]. For the exposed reasons a higher water content is necessary in the production of recycled mortar mixes, a fact noted in this work.

\subsubsection{Water retentivity}

The water retentivity results are presented in Table 3. All the mortar mixes (including those produced using recycled aggregate), except for the CM-LF mortar, achieved the minimum value of $90 \%$ required by Cuban specifications. The lower percentage of fine material in the LF filler compared to that of the LH filler (Fig. 2) and the water retaining ability of LH, influenced strongly on this property $[63,64]$. The recycled aggregate mortars achieved similar or higher water retentivity capacity to that of the control mortar, despite the employment of a lower volume of filler. The finer particle combined with the greater roughness of RA produce a larger specific surface which has the effect of causing a higher amount of water on the surface pores. The result being the creation of a cohesive force, which is prompted by the electrostatic attraction between the positive hydrogen atom and the highly electronegative oxygen atom within a neighboring water molecule

300 (i.e. hydrogen bond) [65]. Neno et al [18] also mentioned that as opposed to sand very 301 fine concrete recycled particles (RCA) must have been retained. The very fine particles of RCA were described as eventually leading on to a filler effect which improved the

303 fresh state. An increase of RCA content within the mortar mixes had the effect of producing a higher water retentivity value. 
$306 \quad 4.2$ Hardened state properties

307 4.2.1 Physical properties

308 Table 4 shows the physical properties achieved by all the mortar mixes. The density and 309 absorption capacity of the recycled aggregate mortars was lower and higher, respectively 310 than that of the control mortars. As a result of the mentioned properties of the recycled 311 aggregate [14,18,20,26,65], the mortars manufactured with RA1-F and RA2-F recycled 312 aggregates presented a lower density than the mortars produced employing recycled 313 aggregates obtained via the crushing of the coarser fraction of CDW (RA1-C/-CF and 314 RA2-C/-CF). The mortar produced employing the RAF-1 aggregate achieved the lowest 315 density and highest absorption capacity. The mortar mixes produced employing RA1-F 316 achieved up to $100 \%$ higher absorption capacity than those of the conventional mortars. 317 A comparative study $[19,66]$ showed that the mortars produced employing recycled 318 aggregates achieved a considerably higher porosity and water absorption capacity value 319 than those of the control mortar. In general, the mortar mixes produced employing LH 320 filler achieved a slightly higher absorption capacity to those of the mortar mixes produced 321 employing the LF filler. The RM1-F-LH and RM1-F-LF mortars achieved values which 322 were twice as great as those of the control mortars.

323 The mortar produced employing RA2-C with LH filler (RM2-C-LH) proved to achieve a 324 higher absorption capacity than the mortar produced employing RA2-F and RA2-CF. The 325 reason for this being its need for a higher water/cement ratio in order to achieve the 326 minimum workability required by Cuban standard.

\subsubsection{Mechanical properties}

329 Figures 5, 6 and 7 show the mechanical property (compressive strength, flexural strength 330 and bond tensile strength, respectively) values of each mortar as well as their 331 corresponding standard deviation.

\section{Compressive strength}

333 The type III masonry mortar (which is adequate for using at ground level and above, as 334 rendering or bonding material) must have a minimum compressive strength value of 5.2 $335 \mathrm{MPa}$ at 28 days in order to comply with the Cuban standard NC 175:2002 [31]. As shown 
336 in Fig. 5, all the mortars achieved the minimum required strength value with the exception 337 of the RM1-F-LF mortar.

338 The recycled mortars achieved a lower compressive strength than those of the 339 conventional mortars, a fact also noted by other researchers[17,67-69]. The mortar mixes 340 produced employing recycled aggregates obtained from the crushing of the coarse type 341 CDW1 (RA1-C) proved to achieve higher strength levels than those produced using the 342 coarse type CDW2 recycled aggregates (RA2-C). The mortars produced employing the 343 RA1-C aggregates achieved a lower than $10 \%$ reduction of compressive strength with 344 respect to that of conventional mortar.

345 The recycled mortars produced employing the aggregates obtained from the fine fraction 346 of the CDW (RA1-F, RA2-F) proved to achieve the lowest strength values. These mortars 347 achieved a reduction in strength value of up to $40 \%$ in the mortars produced with RA1-F 348 and up to $35 \%$ in the mortars produced with RA2-F. It must be noted that although the 349 four mortars, RM1-F-LH, RM2-F-LH, RM1-F-LF and RM2-F-LF, were produced using 350 a lower w/c ratio to that of the other recycled mortars (in order to obtain adequate workability). A determining factor on the compressive strength of the four mentioned mortars was the poor quality of the recycled aggregates employed in their production. It is known that with respect to conventional mortars the low w/c ratio produces higher strength values. However, this water/cement ratio parameter cannot be considered as an appropriate means of predicting recycled aggregate mortar's strength. This fact has also been noted in other works $[65,70]$.

357 In all cases, the mortar mixes manufactured with LF filler achieved lower compressive 358 strength values than those produced employing LH filler, this was due to its low binder 359 property and coarser fraction. It is known [24] that the improvement of the mechanical 360 strength of the mortars is related to the incorporation of fines within the mortar mixes.

361 Nevertheless, it must be noted that all the mortar mixes manufactured with recycled 362 aggregates obtained by crushing the coarse fraction of the CDW achieved the minimum 363 required values of compressive strength established by Cuban specifications. This 364 denotes the possibility of the total replacement of natural aggregates by those of recycled aggregates with respect to type III mortar production. Certain research $[16,18,26,63]$ also

366 described the possibility of the total substitution of natural aggregate by recycled 367 aggregates for masonry mortar production. 
369 Flexural strength is not considered a restricted property according to Cuban specification requirements. A comparative study proved that most of the recycled mortars achieved lower flexural strength when compared to natural aggregate mortars, a fact noted by other researchers [16,42,67,69,71]. Nevertheless, all the mortars produced employing LH achieved a higher strength value than their corresponding LF mortars. The control and RM1-C-LH mortars produced employing hydrated lime filler achieved the same strength values. The mortars produced employing RA1-F/-CF and RA2-F/-CF achieved lower strength values than those of the mortar mixes produced by employing recycled aggregates obtained solely from the coarse fraction (nominated -C) of CDW (see Fig. 6). The mortars produced employing RA1-F/-CF and RA2-F/-CF with LH as the filler achieved a reduction of up to $33 \%$ and up to $45 \%$ respectively, with respect to CM-LH. The mortar produced employing the previous aggregates and LF as a filler achieved a reduction of up to $48 \%$ and $55 \%$ respectively, with respect to the CM-LF mortar.

382 Similarly, with regard to compressive strength values, no relation between the total w/c 383 ratio and the flexural strength of mortars was found. This fact has also been reported in previous works $[16,60]$.

385 According to Vegas et al. [19], Jimenez et al. [20], and Ledesma et al. [15,68], mortars produced employing recycled aggregates of up to $25 \%, 30 \%$ and $40 \%$, respectively, in substitution of natural aggregates obtained similar strength values to those of the control mortars. According to Lopez Gayarre [26] the flexural strength of the recycled aggregate mortar increased with the percentage of recycled ceramic aggregates employed in its manufacture. Neno et al. [18], also related this as happening when employing $100 \%$ of recycled concrete aggregates and verified that this was undoubtedly caused by the reduction that the amount of effective water experienced when the percentage of recycled aggregate for natural aggregate substitution was increased.

Bond tensile strength

According to Cuban regulation NC 175:2002 [31], $0.3 \mathrm{MPa}$ is the minimum bond strength value required for type III masonry mortars. That value could be reduced to $0.2 \mathrm{MPa}$ when the masonry mortars are employed as rendering or bonding for interior walls.

398 Fig. 7 shows the bond strength results obtained by all the mortars as well as the two restrictive values. All the recycled mortars were found to have obtained a lower bond 
tensile strength than that of the mortars produced employing natural aggregates. The recycled mortars manufactured with aggregates obtained from the CDW-1 source (mainly of ceramic composition), were found to achieve higher bond strength values than the mortars produced with aggregates from the CDW-2 source (heterogeneous source containing mortar, low quality concrete composition and ceramic material). Moreover, the use of recycled aggregates obtained via the crushing of the coarse material within the CDW (RA1-C) achieved the highest property values. According to certain researchers $[14,16]$, recycled aggregate mortars achieve a lower bond strength capacity than that of control mortars. In contrast, several researchers $[42,67,69,72]$ have determined that mortars produced employing $100 \%$ of recycled aggregate replacement ratio could achieve a higher bond strength values than that of the control mortar.

411 The use of LF filler in substitution of LH filler caused a reduction of the bond strength,

412 although the highest reduction took place in the mortar produced with natural aggregates.

413 The binder effect of the LH resulted in the increase of the mortars' adhesive capacity [71].

414 The mortars produced employing RA1-F and RA2-F recycled aggregates achieved the 415 lowest bond results. The reduction of bond strength of mortars produced employing LH 416 and LF using RA-F reached levels of up to $45 \%$ and $35 \%$, respectively, with respect to 417 the conventional mortars produced with the corresponding filler.

418 All mortars achieved the 0.2 MPa value established by Cuban standard for rendering 419 mortars which are as suitable for employment on interior walls. However, the RM2-F420 LH, RM1-F-LF and RM2-F-LF mortars, produced employing recycled aggregates RA-F, 421 which were obtained from the fine CDW fraction, did not reach the minimum strength of $4220.3 \mathrm{MPa}$ needed for type III masonry mortar.

\subsubsection{Durability properties}

\section{Capillary absorption}

426 Fig. 8 and Fig. 9 indicate the capillary absorption values of the different mortars tested. 427 According to the obtained results, the final capillary absorption value was greatly 428 influenced by the water absorption capacity of the recycled aggregates (see Table 1), a 429 fact which has also been verified by other researchers [18-20,69]. According to Lopez 430 Gayarre et al. [26], the recycled mortar produced with $100 \%$ of ceramic recycled 431 aggregates achieved lower capillary absorption capacity than those of the conventional 
mortar due to the decrease in the amount of effective water. This decrease being a direct

433 result of an increase in the percentage of the ceramic recycled aggregates employed in the 434 production of the mortar.

435 In this case, all mortars showed similar behavior at 7 hours of testing. However, at 72 436 hours of testing the difference of the high absorption capacity of the recycled aggregates 437 in comparison to those of the natural aggregates was notable. Nevertheless, after 168 438 hours of testing, the mortars produced employing the recycled aggregates with the highest water absorption capacity, RM1-F and RM2-F achieved the highest capillary absorption values. The RM1-C-LH and RM1-CF-LH recycled mortars were the mortars which of all the other recycled mortars obtained the lowest capillary absorption capacity values. However, these achieved values were higher than those of the conventional mortar CMLH, which obtained the lowest value.

444 Fig.8 and Fig. 9 denote the capillary absorption of the mortars produced employing 445 limestone filler (LF), which proved to have a higher capillary absorption capacity in the 446 early stages of testing than those of the mortars produced with hydrated lime (LH). The 447 reason for this difference in capillary absorption was due to the low transfer sorptivity 448 and high water retaining characteristics of hydrated lime [64]. Nevertheless, after 168 449 hours of testing it was determined that the capillary absorption of the mortars depended 450 on the type of aggregates employed in the mortar production and not on the type of filler 451 used. At 168 hours of testing, the capillary absorption values of all the mortars were 452 analyzed. The analysis was carried out by dividing the mortars into in three groups: Group 4531 describes the mortars produced employing the RA1-F recycled aggregate, the RM1-F454 LH and RM1-F-LF mortars, which achieved the highest values; Group 2 describes the 455 behavior of all the other recycled aggregate mortars, which all proved to have achieved 456 similar capillary absorption; Finally, Group 3 describes the control mortars, CM-LF and 457 CM-LH, which achieved the lowest capillary absorption values of all the mortars tested.

458 The capillary absorption values of the mortars from group 1, 2 and 3 were 6, 5 and 4 $459 \mathrm{~g} / \mathrm{cm}^{2}$ at $168 \mathrm{~h}$, respectively. The test results imply that the final value of the capillary 460 absorption (at $168 \mathrm{~h}$ ) depended directly on the water absorption of the recycled aggregate 461 which was employed in the mortar manufacture [60,63]. There was no significant 462 difference noted on the capillary absorption values when LH or LF filler was employed 463 for mortar production. 
465 The mortars produced employing recycled aggregates suffered a higher shrinkage than 466 the mortars manufactured employing natural aggregates (see Fig. 10 and Fig. 11). This was due to their greater water absorption capacity. This difference in levels of shrinkage has also been described by several researchers $[16,18,68,73]$.

469 Silva et al. [61], found that mortars employing 20\%, 50\% and 100\% of ceramic recycled 470 aggregates achieved similar shrinkage values amongst themselves, but those values were 471 higher than those obtained by the control mortar. According to Vegas et al. [19], Cabrera472 Covarrubias et al. [74], Jimenez et al [20], and Lopez Gayarre et al. [26] the mortar 473 produced employing up to $25 \%, 30 \%, 40 \%$, and $50 \%$ respectively, of ceramic aggregates 474 achieved acceptable shrinkage values when compared to the same values obtained by 475 conventional mortars.

476 Although the mortars produced using LH filler proved to have higher shrinkage values 477 than those of the mortars manufactured with limestone filler (LF), they were found to 478 achieve the minimum required workability using less water content than the mortars 479 incorporating LF. A comparative study between the LH filler and the LF filler showed 480 that the higher quantity of material finer than $75 \mu \mathrm{m}$ in the LH filler and its water retaining 481 capacity proved to have a great influence on the increase of the shrinkage value. This fact has also been described by other researchers [70,75].

483 All the recycled mortars produced using LF filler achieved similar shrinkage values in 484 spite of the different composition and properties of the recycled aggregates employed. 485 According to Miranda and Selmo [75], the use of different percentages of recycled 486 aggregates was influential on the mortars' shrinkage but not on their composition.

\section{Electrical resistivity}

488 Fig. 12 indicates the electrical resistivity values of all the studied mortars. All the mortars achieved a low resistivity value as a result of their high absorption capacity and low mechanical properties. However, all the recycled mortars, with the exception of those mortars produced employing RA1-F and RA2-F aggregates, achieved a higher resistivity level than those of the control mortars.

493 In all probability, the presence of ceramic material in the recycled aggregates explains the

494 higher value achievement of the recycled mortars when compared to the same values 495 obtained from the control mortars. Similar results to those exposed have been reported in 
a previous study [14]. The coarse fraction of the CDW contained a higher percentage of ceramic material than the fine fraction. CDW-1 proved to have the highest amount of this ceramic material, and it was this ceramic content which caused the highest electrical resistivity levels in these mortars due to its inherent electrical insulating properties.

500 Consequently, the property of electrical resistivity is not an adequate form of assessing 501 the quality of mixed recycled aggregates mortars, as the values reported are more affected

502 by the content of siliceous material than by the saturated porous ramification.

\section{Conclusions}

505 The following conclusions and recommendations for the use of RA and filler in masonry mortar can be drawn from the results of this study:

Recycled aggregates:

- For the adequate quality of the RA1 recycled aggregates production, a coarse fraction ( $>4.76 \mathrm{~mm}$ ) of the CDW1 is required. Taking into consideration in this study that the main component of the CDW1 was ceramic, with soil and limestone as the finest materials and minor components and with the complete absence of concrete.

- When the main component of the CDW is concrete combined with a low amount of impurities, the recycled aggregate produced employing only the fine fraction

Fresh state of recycled aggregate mortars: of CDW $(<4.76 \mathrm{~mm})$ achieved similar properties to those produced crushing the

Hardened state of recycled aggregate mortars: was mainly composed of earth and limestone, increased the mortars' absorption 
it was necessary to employ the ceramic material presented in the coarse fraction of CDW for recycled aggregate production.

- Whereas the mortars produced employing recycled aggregate obtained from the CDW1, which had ceramic as its main component, achieved similar mechanical properties to conventional mortar, it was discovered that the use of the recycled aggregates obtained from CDW2 (concrete with main component) achieved lower properties than those of conventional one.

- The employment of LH filler as opposed to LF can result in 50\% higher strength mortars than those of mortars made with LF employing the same type of recycled aggregates.

- Although recycled aggregate mortars achieved a higher shrinkage value than that of conventional mortars, the employment of LF filler in recycled aggregate mortars reduced the shrinkage achieved by mortars produced with LH by up to $25 \%$.

544 established for recycled aggregate mortars, it is necessary to employ the coarse fraction 545 of the CDW in recycled aggregate production. Test results of the RA-F (recycled 546 aggregates produced using only the fine fraction of CDW) determined that it was only

547 adequate for the rendering or bonding of interior walls at or above ground level.

548 Although the mortars produced employing hydrated lime achieved higher mechanical 549 properties than those of the mortars produced using limestone filler, it was established 550 that both, the physical properties and the shrinkage values, of the mortars produced employing the limestone filler were more adequate. A finer grading distribution of the limestone filler (only $40 \%$ of the available LF is finer than $75 \mu \mathrm{m}$ ) could be responsible

553 for improving both the retentivity and the mechanical properties of the mortars assuring 554 a general improvement of properties of masonry recycled mortars.

556 Acknowledgements

557 The authors would like to thank the Spanish Agency of International Cooperation for 558 Development (AECID) and The Ministry of Exterior Affairs and Cooperation for the 
financial support given to the above research work. The authors also thank the GREAT project code PIRSES-GA-2013-612665 for financial support.

561

\section{Reference}

563

[1] J.S. Damtoft, J. Lukasik, D. Herfort, D. Sorrentino, E.M. Gartner, Sustainable development and climate change initiatives, Cem. Concr. Res. 38 (2008) 115-127. doi:10.1016/j.cemconres.2007.09.008.

[2] H. Yuan, L. Shen, Trend of the research on construction and demolition waste management, Waste Manag. 31 (2011) 670-679. doi:10.1016/j.wasman.2010.10.030.

[3] N. Kisku, H. Joshi, M. Ansari, Panda S K, Sanket Nayak, Sekhar Chandra Dutta, A critical review and assessment for usage of recycled aggregate as sustainable construction material, Constr. Build. Mater. 131 (2017) 721-740. doi:10.1016/J.CONBUILDMAT.2016.11.029.

[4] R.O. Neto, P. Gastineau, B.G. Cazacliu, L. Le Guen, R.S. Paranhos, C.O. Petter, An economic analysis of the processing technologies in CDW recycling platforms, Waste Manag. 60 (2017) 277-289. doi:10.1016/J.WASMAN.2016.08.011.

[5] A. Ossa, J.L. García, E. Botero, Use of recycled construction and demolition waste (CDW) aggregates: A sustainable alternative for the pavement construction industry, J. Clean. Prod. $135 \quad$ (2016) 379-386. doi:10.1016/J.JCLEPRO.2016.06.088.

[6] M.D. Bovea, J.C. Powell, Developments in life cycle assessment applied to evaluate the environmental performance of construction and demolition wastes, Waste Manag. 50 (2016) 151-172. doi:10.1016/J.WASMAN.2016.01.036.

[7] R.V. Silva, J. de Brito, R.K. Dhir, The influence of the use of recycled aggregates on the compressive strength of concrete: a review, Eur. J. Environ. Civ. Eng. 19 (2015) 825-849. doi:10.1080/19648189.2014.974831.

[8] L. Evangelista, J. de Brito, Concrete with fine recycled aggregates: a review, Eur. J. Environ. Civ. Eng. 18 (2014) 129-172. doi:10.1080/19648189.2013.851038.

[9] D. Pedro, J. de Brito, L. Evangelista, Influence of the use of recycled concrete aggregates from different sources on structural concrete, Constr. Build. Mater. 71 (2014) 141-151. doi:10.1016/j.conbuildmat.2014.08.030.

[10] A. Gonzalez-Corominas, M. Etxeberria, Effects of using recycled concrete 
aggregates on the shrinkage of high performance concrete, Constr. Build. Mater. 115 (2016) 32-41. doi:10.1016/j.conbuildmat.2016.04.031.

[11] M.M. Tüfekçi, Ö. Çakir, An Investigation on Mechanical and Physical Properties of Recycled Coarse Aggregate (RCA) Concrete with GGBFS, Int. J. Civ. Eng. 15 (2017) 549-563. doi:10.1007/s40999-017-0167-x.

[12] Y.-J. Fan, B.-S. Yu, S.-L. Wang, Analysis and Evaluation of the Stochastic Damage for Recycled Aggregate Concrete Frames Under Seismic Action, Int. J. Civ. Eng. (2017). doi:10.1007/s40999-017-0203-X.

601

[13] L. Restuccia, C. Spoto, G. Andrea Ferro, J.-M. Tulliani, Recycled Mortars with

602 C\&D Waste, Procedia Struct. Integr. 2 (2016) 2896-2904. doi:10.1016/j.prostr.2016.06.362.

603

[14] I. Martínez, M. Etxeberria, E. Pavón, N. Díaz, A comparative analysis of the 604

[15] E.F. Ledesma, J.R. Jiménez, J.M. Fernández, a. P. Galvín, F. Agrela, a. Barbudo, 607 Properties of masonry mortars manufactured with fine recycled concrete aggregates, Constr. Build. Mater. 71 (2014) 289-298. doi:10.1016/j.conbuildmat.2014.08.080.

[16] P. Saiz Martínez, M. González Cortina, F. Fernández Martínez, A. Rodríguez Sánchez, Comparative study of three types of fine recycled aggregates from

[17] Z. Zhao, S. Remond, D. Damidot, W. Xu, Influence of fine recycled concrete aggregates on the properties of mortars, Constr. Build. Mater. 81 (2015) 179-186. doi:10.1016/j.conbuildmat.2008.06.007.

[18] C. Neno, J. De Brito, R. Veiga, Using fine recycled concrete aggregate for mortar production, Mater. Res. 17 (2014) 168-177. doi:http://dx.doi.org/10.1590/S151614392013005000164.

[19] I. Vegas, I. Azkarate, A. Juarrero, M. Frías, Design and performance of masonry mortars made with recycled concrete aggregates, Mater. Construcción. 59 (2009) 5-18. doi:10.3989/mc.2009.44207. aggregates from ceramic waste in masonry mortar manufacturing, Constr. Build. 
Mater. 40 (2013) 679-690. doi:10.1016/j.conbuildmat.2012.11.036.

[21] E. Dapena, P. Alaejos, a. Lobet, D. Pérez, Effect of Recycled Sand Content on Characteristics of Mortars and Concretes, J. Mater. Civ. Eng. 23 (2011) 414-422. doi:10.1061/(ASCE)MT.1943-5533.0000183.

630

[22] F.G. Cabrera-Covarrubias, J.M. Gómez-Soberón, J.L. Almaral-Sánchez, S.P.

[23] J. Silva, J. de Brito, R. Veiga, Incorporation of fine ceramics in mortars, Constr. Build. Mater. 23 (2009) 556-564. doi:10.1016/j.conbuildmat.2007.10.014.

[24] M. Braga, J. De Brito, R. Veiga, Incorporation of fine concrete aggregates in mortars, Constr. Build. Mater. $36 \quad$ (2012) 960-968.

[26] F. López Gayarre, Í. López Boadella, C. López-Colina Pérez, M. Serrano López, A. Domingo Cabo, Influence of the ceramic recycled agreggates in the masonry

[28] H. McWilliams, C.T. Griffin, A critical assessment of concrete and masonry structures for reconstruction after seismic events in developing countries, in: P. Cruz (Ed.), Struct. Archit. Concepts, Appl. Challenges, CRC Press, Boca Raton, 2013: pp. 857-864.

[29] E. Pavón, I. Martínez, M. Etxeberria, The production of construction and demolition waste material and the use of recycled aggregates in Havana, Cuba, Rev.

Fac.

Ing.

(2014)

$167-178$. http://aprendeenlinea.udea.edu.co/revistas/index.php/ingenieria/article/view/1551 6.

[30] I. Muñoz Fernández, Estudio económico y ambiental del cambio de la gestión de residuos de construcción y demolición en la ciudad de La Habana, Master Thesis 
by Miren Etxeberria \& Alvar Garola, Universidad Politécnica de Cataluña (UPC),

2012, Universidad Politécnica de Cataluña, 2012. http://upcommons.upc.edu/handle/2099.1/14827.

663

[31] NC 175: 2002, Morteros de albañilería. Especificaciones, Cuba, 2002.

664

[32] ASTM C 270-12a, Standard Specifications for Mortars for Unit Masonry, USA,

665 2012

666 [33] NC 95: 2001, Cemento Portland. Especificaciones, Cuba, 2001.

667 [34] BS EN 932-1:1997, Tests for general properties of aggregates. Methods for 668 sampling, 1997.

669

[35] NC 178: 2002, Áridos. Análisis granulométrico, Cuba, 2002.

670

[36] ASTM C136/136M-14, Standard Test Method for Sieve Analysis of Fine and Coarse Aggregates, USA, 2014.

672

[37] NC 177: 2002, Áridos. Determinación del porciento de huecos, Cuba, 2002.

673

[38] ASTM C29/C29M-17, Standard Test Method for Bulk Density ("Unit Weight") and Voids in Aggregate, American Society for Testing and Materials, USA, 2017.

[39] NC 181: 2002, Áridos. Determinación del peso volumétrico, Cuba, 2002.

[40] NC 182: 2002, Áridos. Determinación del material más fino que el tamiz de $0.074 \mathrm{~mm}$, Cuba, 2002.

[43] L. Evangelista, J. De Brito, Durability performance of concrete made with fine recycled concrete aggregates, Cem. Concr. Compos. 32 (2010) 9-14. doi:10.1016/j.cemconcomp.2009.09.005.

[44] L. Evangelista, M. Guedes, J. de Brito, a. C. Ferro, M.F. Pereira, Physical, chemical and mineralogical properties of fine recycled aggregates made from concrete waste, Constr. Build. Mater. 86 (2015) 178-188. doi:10.1016/j.conbuildmat.2015.03.112.

[45] A.K.H. Kwan, M. McKinley, Effects of limestone fines on water film thickness, paste film thickness and performance of mortar, Powder Technol. 261 (2014) 3341. doi:10.1016/J.POWTEC.2014.04.027. 
694 [46] NC 173: 2002, Mortero endurecido. Determinación de la resistencia a flexión y

695

696

697

698

699

700

701

702

703

704

705

706

707

708

709

710

711

712

713

714

715

716

717

718

719

720

721

722

723

724

725

726

727 compresión, 2002.

[47] ASTM C348-14, Standard Test Method for Flexural Strength of Hydraulic-Cement Mortars, American Society for Testing and Materials, USA, 2014.

[48] ASTM C349-14, Standard Test Method for Compressive Strength of HydraulicCement Mortars (Using Portions of Prisms Broken in Flexure), American Society for Testing and Materials, USA, 2014.

[49] NC 170: 2002, Mortero fresco. Determinación de la consistencia en la mesa de sacudidas, 2002.

[50] ASTM C1437-15, Standard Test Method for Flow of Hydraulic Cement Mortar, American Society for Testing and Materials, USA, 2015.

[51] DIN 4226-100:2002-02, Aggregates for concrete and mortar - Part 100: Recycled aggregates, Germany, 2002.

[52] NC 186: 2002, Arena. Peso específico y absorción de agua, Cuba, 2002.

[53] ASTM C128-97, Test Method for Specific Gravity and Absorption of Fine Aggregate, American Society for Testing and Materials, USA, 1997.

[54] NC 169: 2002, Mortero fresco. Determinación de la capacidad de retención de agua, Cuba, 2002.

[55] ASTM C1506-16b, Standard Test Method for Water Retention of Hydraulic Cement-Based Mortars and Plasters, American Society for Testing and Materials, USA, 2016.

[56] NC 172: 2002, Mortero endurecido. Determinación de la resistencia a la adherencia por tracción, 2002.

[57] NC 171: 2002, Mortero endurecido. Determinación de la absorción de agua por capilaridad, 2002.

[58] ASTM C1403-15, Standard Test Method for Rate of Water Absorption of Masonry Mortars, American Society for Testing and Materials, USA, 2015.

[59] ASTM C490/C490M-11, Standard Practice for Use of Apparatus for the Determination of Length Change of Hardened Cement Paste, Mortar, and Concrete, American Society for Testing and Materials, USA, 2011.

[60] G.M. Cuenca-Moyano, M. Martín-Morales, I. Valverde-Palacios, I. ValverdeEspinosa, M. Zamorano, Influence of pre-soaked recycled fine aggregate on the properties of masonry mortar, Constr. Build. Mater. 70 (2014) 71-79. doi:10.1016/j.conbuildmat.2014.07.098. 
[61] J. Silva, J. de Brito, R. Veiga, Recycled Red-Clay Ceramic Construction and Demolition Waste for Mortars Production, J. Mater. Civ. Eng. 22 (2010) 236-244. doi:10.1061/(ASCE)0899-1561(2010)22:3(236).

[62] G.S. Wong, A.M. Alexander, R. Haskins, T.S. Poole, P.G. Malone, L. Wakeley, Portland-cement concrete rheology and workability: final report, McLean: US Department of Transportation and Office of Infrastructure Research and Development, 2001.

[63] R. V Silva, J. de Brito, R.K. Dhir, Performance of cementitious renderings and masonry mortars containing recycled aggregates from construction and demolition wastes, Constr. Build. Mater. 105 (2016) 400-415. doi:10.1016/j.conbuildmat.2015.12.171.

[64] C. Ince, S. Derogar, N.Y. Tiyakioglu, Y.C. Toklu, The influence of zeolite and powdered Bayburt stones on the water transport kinetics and mechanical properties of hydrated lime mortars, Constr. Build. Mater. 98 (2015) 345-352. doi:10.1016/J.CONBUILDMAT.2015.08.118.

[65] R. Raeis Samiei, B. Daniotti, R. Pelosato, G. Dotelli, Properties of cement-lime mortars vs. cement mortars containing recycled concrete aggregates, Constr. Build. Mater. 84 (2015) 84-94. doi:10.1016/j.conbuildmat.2015.03.042.

[66] I. Martínez, M. Etxeberria, E. Pavón, N. Díaz, Analysis of the properties of masonry mortars made with recycled fine aggregates for use as a new building material in Cuba, Rev. La Constr. 15 (2016) 9-21.

[67] C. Poon, S. Kou, Properties of cementitious rendering mortar prepared with recycled fine aggregates, J. Wuhan Univ. Technol. Sci. Ed. 25 (2010) 1053-1056. doi:10.1007/s11595-010-0148-2.

[68] E.F. Ledesma, J.R. Jiménez, J. Ayuso, J.M. Fernández, J. de Brito, Maximum feasible use of recycled sand from construction and demolition waste for ecomortar production - Part-I: ceramic masonry waste, J. Clean. Prod. 87 (2015) 692706. doi:10.1016/j.jclepro.2014.10.084.

[69] S.-C. Kou, C.-S. Poon, Effects of different kinds of recycled fine aggregate on properties of rendering mortar, J. Sustain. Cem. Mater. 2 (2013) 43-57. doi:http://dx.doi.org/10.1080/21650373.2013.766400.

[70] M. Braga, J. Brito, R. Veiga, Reduction of the cement content in mortars made with fine concrete aggregates, Mater. Struct. 47 (2014) 171-182. doi:10.1617/s11527-013-0053-1. 
762 [71] M. Stefanidou, E. Anastasiou, K. Georgiadis Filikas, Recycled sand in lime-based

[72] V. Corinaldesi, Mechanical behavior of masonry assemblages manufactured with recycled-aggregate mortars, Cem. Concr. Compos. 31 (2009) 505-510. doi:10.1016/j.cemconcomp.2009.05.003.

[73] H.. Mesbah, F. Buyle-Bodin, Efficiency of polypropylene and metallic fibres on control of shrinkage and cracking of recycled aggregate mortars, Constr. Build. Mater. 13 (1999) 439-447. doi:10.1016/S0950-0618(99)00047-1.

[74] F.G. Cabrera-Covarrubias, J.M. Gómez-Soberón, J.L. Almaral-Sánchez, S.P. Arredondo-Rea, R. Corral-Higuera, Mechanical properties of mortars containing recycled ceramic as a fine aggregate replacement, Rev. La Constr. 14 (2015) 2229.

[75] L. Miranda, S. Selmo, CDW recycled aggregate renderings : Part I - Analysis of the effect of materials finer than $75 \mathrm{~lm}$ on mortar properties, Constr. Build. Mater. 20 (2006) 615-624. doi:10.1016/j.conbuildmat.2005.02.025. 